\title{
Newly synthesized RNA Sequencing Characterizes Transcription Dynamics in Three Pluripotent States
}

Rui Shao1,2, Banushree Kumar ${ }^{1,2}$, Katja Lidschreiber ${ }^{3,4}$, Michael Lidschreiber ${ }^{3,4}$, Patrick Cramer $^{3,4}$, Simon J. Elsässer ${ }^{1,2, *}$

${ }^{1}$ Science for Life Laboratory, Department of Medical Biochemistry and Biophysics, Division of Genome Biology, Karolinska Institutet, Tomtebodavagen 23, 17165 Stockholm, Sweden.

${ }^{2}$ Ming Wai Lau Centre for Reparative Medicine, Stockholm node, Karolinska Institutet, Solnavägen 9, 17165 Stockholm, Sweden

${ }^{3}$ Department of Biosciences and Nutrition, Karolinska Institutet, Neo, 14183 Huddinge, Sweden. ${ }^{4}$ Department of Molecular Biology, Max Planck Institute for Biophysical Chemistry, Am Fassberg 11, 37077 Göttingen, Germany

*correspondence: simon.elsasser@scilifelab.se

Unique transcriptomes define naïve, primed and paused pluripotent states in mouse embryonic stem cells. Here we perform transient transcriptome sequencing (TT-seq) to de novo define and quantify coding and non-coding transcription units (TUs) in different pluripotent states. We observe a global reduction of RNA synthesis, total RNA amount and turnover rates in ground state naïve cells ( $2 \mathrm{i}$ ) and paused pluripotency (mTORi). We demonstrate that elongation velocity can be reliably estimated from TT-seq nascent RNA and RNA polymerase II occupancy and observe a transcriptome-wide attenuation of elongation velocity in the two inhibitor-induced states. We also discover a relationship between elongation velocity and termination readthrough distance. Our analysis suggests that steady-state transcriptomes in mouse ES cells are controlled predominantly on the level of RNA synthesis, and that signaling pathways governing different pluripotent states immediately control key parameters of transcription. 


\section{INTRODUCTION}

Pluripotency in the pre-implantation embryo is of transient nature in vivo, but embryonic stem cells can be cultured long-term in stable and interconvertible pluripotent states in vitro: in serum/leukemia inhibitory factor (LIF) media (SL, serum-primed state), serum-free media containing LIF, Mek1/2 and GSK3 $\beta$ inhibitors (2i, naïve/ground state) or serum/LIF media with mTOR inhibitor (mTORi, paused state). The $2 \mathrm{i}$-induced ground state resembles naïve preimplantation E4.5 epiblast cells (Ying et al, 2008; Ghimire et al, 2018). Global rewiring of signaling, metabolism and epigenome have been observed in the SL-2i transition. CpG methylation is dramatically decreased genome-wide, concomitant with a broad increase in H3K27me3 (Walter et al, 2016; Kumar \& Elsässer, 2019). Further, a reduction of global H3K4me3 levels results in diminished promoter bivalency of developmentally regulated genes, where H3K27me3 and H3K4me3 are thought to set up a poised state (Sachs et al, 2013; Marks et al, 2012; Kumar \& Elsässer, 2019; Atlasi \& Stunnenberg, 2017). Enhancer activity is rewired during the SL-2i transition via Esrrb binding and H3K27ac activation (Atlasi et al, 2019). mTOR inhibition suppresses cell growth and division while retaining pluripotency, resembling the diapaused blastocysts in vivo (Bulut-Karslioglu et al, 2016).

While most studies have focused on rewiring of regulatory circuits, activating or disengaging individual enhancers and transcripts, $2 \mathrm{i}$ and mTORi states also exhibit dramatically lower total cellular mRNA and attenuated transcription activity revealed by cell-numbernormalized RNA-seq and EU (5-Ethynyl Uridine) incorporation (Bulut-Karslioglu et al, 2016). Given that transcript levels are balanced by rates of RNA synthesis and degradation (Schwalb et al, 
2016; Herzog et al, 2017), to which extent transcription activity itself influences transcript abundance remains to be addressed. Quantitative RNA labeling techniques enable the absolute measurements of either RNA synthesis or degradation (Schwalb et al, 2016; Schwanhäusser et al, 2011; Rabani et al, 2011; Herzog et al, 2017; Muhar et al, 2018; Schofield et al, 2018). To uncover the transcription and chromatin interplay in SL-2i and SL-mTORi transitions, we measured both total and nascent RNA with TT-seq and estimated RNA turnover using spike-in references. We de novo annotated known and new transcription units (TUs) and examined how transcription of different TUs responds to state transitions. Our data reveals how the balance of RNA synthesis and dilution by cell growth/division shapes total RNA abundance in different pluripotent states. We also estimate RNA polymerase (Pol) II elongation velocity, characterize its manifestation in epigenomic features, and validate its impact on termination read-through distance.

\section{Results}

Transcription unit annotation in mESC pluripotent states. To capture newly synthesized RNA in different pluripotent states and transitions, we switched ES cells from SL medium to $2 \mathrm{i}$ medium for 2 or 7 days, mTORi medium for 1 or 2 days, pulsed $4 s U$ (4-thiouridine) for 5 minutes and performed the TT-seq method as previously described (Schwalb et al, 2016) (Fig 1A). In order to verify our nascent RNA sequencing results, we compared gene coverage with GRO-seq (global run-on sequencing) (Flynn et al, 2016; Wang et al, 2015), PRO-seq (precision run-on sequencing) (Engreitz et al, 2016; Lloret-Llinares et al, 2018), NET-seq (native elongating transcript sequencing) (Mylonas \& Tessarz, 2018; Tuck et al, 2018), 4sU-seq (Benabdallah et al, 2019; Brown 
et al, 2017) and Bru-seq (bromouridine sequencing) (Ardehali et al, 2017). Due to the short labeling time and fragmentation step included in the protocol, TT-seq nascent RNA showed a steadt coverage over the gene body, balanced signal from the first to the last exons as well as the highest intron/exon coverage ratio (Fig 1B, Fig EV1A-B). Thus, a stranded TT-seq signal provides an excellent demarcation of the nascent transcription unit and polymerase-independent measure of transcriptional activity.

The pluripotent ES cell genome is pervasively transcribed (Efroni et al, 2008). We used nascent TT-seq signal to de novo define coding and non-coding TUs in the pluripotent genome separately for each condition and replicate. An R shiny application (TU filter) was developed offering previously described algorithms for TU discovery (Schwalb et al, 2016) within a simple and reproducible visual workflow (Materials and Methods). Overall, $96 \%$ of the uniquely mapped TT-seq nascent RNA reads could be assigned to 11743 GENCODE protein-coding genes, while approximately $1.5 \%$ were assigned to 20437 new intergenic RNAs called from TT-seq (Fig 1C). We automatically annotated TUs by their location and direction relative to transcription start site (TSS) or transcription termination site (TTS) of protein-coding TUs: upstream antisense (uaRNA), convergent (conRNA), cis-antisense (asRNA), downstream sense (dsRNA), downstream antisense (daRNA) TUs (Fig EV2A). An example of the TU annotation is shown for the Tbx3 gene neighborhood (Fig 1B). The sensitivity of our TU discovery pipeline is majorly determined by sequencing depth (Fig EV1C), thus accuracy of TU calling with TU filter relies on continuous read coverage at sufficient depth. Transcription of intergenic TUs was generally lower, suggesting that their cryptic/non-canonical promoters are generally weaker than divergent gene promoters (Fig 
1C). Non-coding RNAs synthesized from the opposite strand of known genes were lowly transcribed (Fig 1D). Thus, lower expressed classes of intergenic RNAs generally exhibited higher inconsistency between replicates (Fig EV2C). uaRNAs, commonly arising from divergent transcription initiation at gene promoters, were most robustly called and relatively abundant amongst non-coding nascent transcripts (Fig 1C, Fig EV1C).

We also applied the same annotation process to published GRO-seq and PRO-seq to test if lowly expressed TUs were recapitulated across methods. TT-seq identified a lower number of nonannotated and method-specific short ncRNAs compared to GRO-seq and PRO-seq, reflecting the different labeling preferences of metabolic and run-on labeling approaches (Fig EV1D-F). Using ChIP-Seq profiles of RNA polymerase (Pol) subunits (Materials and Methods), TUs could be assigned to Pol I, II or III transcripts, albeit in many cases available occupancy profiles were insufficient to unequivocally link the TU to only one of the polymerases (Fig EV1G-H; Materials and Methods). Intergenic RNAs commonly called with all three methods showed the highest proportion of FANTOM5 enhancers (Andersson et al, 2014), ATAC-seq peaks (Atlasi et al, 2019) and STARR-seq enhancers (Peng et al, 2020), and showed low ChIP co-occupancy of all three RNA polymerase types (Fig EV1I). These results suggest that the majority of intergenic RNAs in mESCs exhibit low RNA polymerase occupancy and transcription frequency.

\section{Attenuated RNA synthesis in $2 i$ and mTORi conditions}


Next, we assessed transcriptional changes associated with $2 \mathrm{i}$ and mTORi transitions using TT-seq nascent RNA measurements. We used spike-ins to scale labeled and total RNA (Fig 1E; Materials and Methods) and confirmed that both transcription and total RNA abundance decreased in $2 \mathrm{i}$ and mTORi states (Bulut-Karslioglu et al, 2016). We approximated cell-level RNA turnover as a function of synthesis and total RNA measurements (Fig 1F) and observed a decrease in global RNA turnover in $2 \mathrm{i}$ and mTORi (Fig 1G). Cell-level RNA turnover is influenced by dilution via cell division, and the observed decrease in $2 \mathrm{i}$ and mTORi is in line with a slow-down of cell cycle progression in the new states (Bulut-Karslioglu et al, 2016). Accordingly, we also observed a downward trend in turnover rate as cell confluency increased (Fig 1G). To exclude the possibility that the different states would have intrinsically different labeling efficiencies, we confirmed similar fractions of spliced nascent transcripts across the three states (Fig 1H) (Wachutka et al, 2019).

\section{Genome context modulation underlies global transcription variation.}

Next, we counted the labeled RNA reads on mRNA, intergenic RNA, uaRNA and asRNA intervals, and compared to $2 \mathrm{i}$, mTORi to SL conditions using spike-in normalization (Fig 2A). Transitioning from SL to mTORi was associated with a homogeneous down-regulation of both mRNA and ncRNA synthesis, while individual mRNAs and intergenic RNAs showed a highly variable response with both up- and down-regulation in 2i. mRNA synthesis remained largely correlated between SL in mTORi condition, irrespective of initial expression level, while intergenic transcripts were more variable (Fig 2B, right). In contrast, $2 \mathrm{i}$ induced a greater extent of rewiring for both mRNAs 
and ncRNAs (Fig 2B, left). Intergenic TUs in general followed the global decrease in transcription in $2 \mathrm{i}$ and mTORi conditions (Fig 2C). A notable exception were bidirectional TUs lacking clear enhancer status, which were up-regulated in $2 \mathrm{i}$ condition relative to the global downward trend (Fig 2A, C). From a chromatin perspective, H3K27me3-repressed/bivalent ChromHMM states exhibited larger coefficients of predicting log2 fold-change for bidirectional than unidirectional intergenic TUs (Fig EV2D). This may indicate low connectivity of spurious intergenic transcription units with nearby genes, and imply a basal suppression through H3K27me3 (Fig EV2E) (Haberle \& Stark, 2018)

To assess the contribution of RNA synthesis to changes in total RNA abundance, we compared the pairwise correlation of the three states' labeled RNA and total RNA length-normalized read counts (log-RPK) (Fig EV2G). mRNA, intergenic RNA and asRNA labeled RNA levels correlated well with their total RNA levels (Fig EV2F), which suggests their total RNA abundance is dominantly regulated via RNA synthesis, and to a lesser extent by degradation, across the three states. This is in line with recent studies demonstrating that rewiring of promoter-enhancer interactions, thus changes in transcriptional activity, explains changes in RNA-seq abundance between SL and $2 \mathrm{i}$ states for many differentially regulated genes (Atlasi et al, 2019; Joshi et al, 2015; Novo et al, 2018).

We wondered whether transcriptional changes of intergenic TUs followed a discernable mechanism. Myc gene expression is known to be strongly attenuated under $2 \mathrm{i}$ treatment (Marks et al, 2012) (Galonska et al, 2015) but is maintained in mTORi (Bulut-Karslioglu et al, 2016), and 
interestingly, we found the same trends to govern neighboring intergenic TUs (Fig 2D). Globally, intergenic TU transcription changes correlated well with transcription changes of neighboring genes $(n=11684)$ in a direction- and proximity-dependent manner (Fig 2E). The highest correlation was observed for transcription changes within the $20 \mathrm{~kb}$ region downstream antisense, thus convergent transcripts of protein-coding genes (Fig 2E, top). Transcriptional changes at protein-coding genes correlated better with transcriptional changes at intergenic TUs overlapping an enhancer state than at other intergenic TUs within $\pm 100 \mathrm{~kb}$ region of the gene (Fig $2 \mathrm{E}$, top-right, Fig EV2H-I). We further validated the observed position regulated gene expression trend in a single-cell RNA-seq dataset (Kolodziejczyk et al, 2015) (Fig EV2J). In summary, our analysis supports a previously reported enhancer-gene position dependent co-regulation of the transcriptome during the SL-2i transition (Atlasi et al, 2019), while mTORi largely preserves relative mRNA levels and therefore exhibits less correlated changes between coding and intergenic transcripts (Fig 2E, bottom).

Estimating elongation velocity with TT-seq and Pol II coverages. TT-seq nascent RNA coverage allows estimation of productive transcription initiation frequencies (Gressel et al), which is defined as the number of Pol II molecules that initiated at the promoter and were successfully released into productive elongation per unit of time. Meanwhile, Pol II ChIP-seq captures the Pol II occupancy on the DNA template in steady state, which depends on the number of polymerases and their elongation velocity (Ehrensberger et al, 2013). Thus, by combining Pol II occupancy 
measurements with TT-seq derived initiation frequencies, Pol II elongation velocities can be derived (Caizzi et al, 2021). Since Pol II S5p (CTD Serine-5 phosphorylation) appears at TSS after the pre-initiation complex dissociation (Søgaard \& Svejstrup, 2007; Glover-Cutter et al, 2009), its signal corresponds most closely to the fraction of productive Pol II amongst the total chromatinengaged Pol II molecules (Steurer et al, 2018). Therefore, we used the ratio of TT-seq density over Pol II S5p density from quantitative, native MINUTE-ChIP collected under the same three conditions, $\mathrm{SL}, 2 \mathrm{i}$ and $\mathrm{mTORi}$ as a proxy for relative transcription elongation velocity (Materials and Methods). TT-seq nascent RNA / Pol II S5p ratio exhibited a deep minimum of estimated transcription velocity after the TSS, indicating promoter proximal pausing (Steurer et al, 2018) (Muse et al, 2007) (Bartman et al, 2019); a flat gene body ratio demonstrated the steady elongation velocity, and our transcription velocity estimation also captured the "getting up to speed" model towards elongation termination (Jonkers et al, 2014; Jonkers \& Lis, 2015) (Fig 3AC).

Next, we closely examined the estimated velocity in SL, and used k-means to cluster the estimated elongation velocity profiles of 10386 protein-coding genes into three groups with slow, medium and fast elongation velocity (Fig 3D, Fig EV3C). Acceleration of elongation velocity towards the TES (transcript end site) was only observed for the slow and medium elongation velocity gene groups (Fig 3D). Beyond the TES, the fast elongation group showed a steeper decline of transcription velocity (Fig 3D, Fig EV3C). Since the genes in the slow and medium elongation velocity groups showed a deeper drop near the TSS, we wondered if this feature was indicative of increased Pol II promoter-proximal pausing. We thus verified this observation by calculating a 
pausing index (Fig 3F, Materials and Methods) and established that promoter-proximal pausing was least prevalent in the fast elongating gene group (Fig 3E).

To validate our velocity estimates, we recalculated elongation velocities from Cdk9 inhibition (Cdk9i) time course GRO-seq experiment (Jonkers et al, 2014) (Materials and Methods). The recalculated velocities agreed with the published velocities but included a larger number of genes (Fig EV4A). Comparing our estimated elongation velocities to the Cdk9i-derived direct elongation velocities revealed a good global correlation (Fig $3 \mathrm{H}$, Pearson's $r=0.425$ ). Thus, the labeled RNA / Pol II S5p ratio provides a general way of estimating elongation velocity transcriptome-wide. In addition, the estimated velocity reversely correlated with Pol II S5p density (Fig 3G, $r=-0.485$ ) but not RNA synthesis rates (Fig 3I, $r=0.065$ ). Therefore, with the assumption that Pol II coverage results from the transcription initiation frequency (RNA synthesis rate) and the elongation velocity (Fig 3L), we reversely estimated RNA synthesis rates from the velocity measured by CDK9 inhibition and Pol II S5p density, and these also agreed with a modest correlation with the actual RNA synthesis rates from our TT-seq data (Fig 3J, $r=0.178$ ). These results manifest the close connectivity of Pol II density with its two determinants, RNA synthesis rate and elongation velocity (Fig 3G, Fig EV3A), while RNA synthesis rate and elongation velocity are independently controlled. Therefore, combining Pol II occupancy and RNA synthesis rate is also able to inform on the local elongation velocity.

\section{Interpretation of elongation velocity in mouse ES cells.}


We compared elongation velocity in $2 \mathrm{i}$ and mTORi cells, and found 2.2 and 3.7 fold decrease in median elongation velocity relative to SL cells (Fig 3K). 2i cells showed a preferential reduction of fast-elongated genes, while mTORi cells slowed down homogeneously (Fig EV4B). To understand the regulation of elongation velocity, we first sought to correlate elongation velocity in SL condition with other epigenomic features. Many active histone modifications have been found to be associated with elongation velocity (Jonkers et al, 2014; Veloso et al, 2014), for instance H3K36me3 and H3K79me2. Using our estimation, we confirmed that these two active marks positively correlated with elongation velocity and identified a positive correlation with several chromatin remodelers (Chd1, Chd2 and Chd9) (Fig 4A). Notably, a recent Cryo-EM structure implicates Chd1 in clearing chromatin in front of the traversing RNA polymerase (Farnung et al, 2021). Moreover, we observed anti-correlation with Polycomb repressive marks (H3K27me3, $\mathrm{H} 2 \mathrm{Aub}$ and Ezh2) histone variant H2A.Z, also shown to negatively associate with pause release (Mylonas et al, 2021) (Fig 4A).

We observe Pol II to travel faster through mRNA and intergenic TUs than uaRNA TUs (Fig 4B). Deriving TU elongation time estimates as elongation velocity divided by TU interval length, we found that Pol II spends the longest time traversing through mRNAs, followed by uaRNAs and intergenic TUs (Fig 4C). When looking at pairs of uaRNA and mRNA arising from a shared promoter region, we found a moderate correlation in estimated elongation velocity and time (Fig 4D-F).

Next we questioned if Pol II pause-release dynamics were connected to elongation velocity or RNA synthesis rate. Transcription initiation frequency is known to weakly anti-correlate with 
promoter-proximal pausing (Sanchez et al, 2018; Gressel et al, 2019; Gressel 2017). Accordingly, we observed this trend consistently in all the three conditions (Fig EV3B). The average pause duration, which corresponds to the time Pol II needs to travel through the promoter-proximal pausing interval, has been found to be 42 seconds in human fibroblasts (Steurer et al, 2018). We approximated and scaled the pause duration with the external scale of GRO-seq measured elongation velocity, and agreed that the median pause durations were 21,37 and 61 seconds for $\mathrm{SL}, 2 \mathrm{i}$ and mTORi cells, respectively (Fig EV4C). Then we examined pause durations in SL and found a good correlation with gene elongation time (Fig 4G). Further, we also observed that the pausing index moderately correlated with pausing time and mRNA elongation time (Fig $4 \mathrm{H}-1$ ). These results indicate that RNA polymerase II pause-release dynamics connects with pausing and elongation duration, while gene body elongation time associates with TSS pausing duration to a larger extent (Fig 4G).

Transcription termination read-through is associated with elongation velocity. In K562 cells, TTseq mapped the ultimate termination sites of $(C / G)(2-6) A$ motifs enrichment around 3kb downstream from the last pA (poly-adenylation) sites (Schwalb et al, 2016). To define genome-wide ultimate termination sites from our TT-Seq data we used a method to determine the maximal density contrast (Fig 5A, Materials and Methods). Next we applied the same algorithm to other transcription readout methods (PRO-seq and Pol II S5p ChIP-Seq), and found that the termination windows agreed with TT-seq results in SL and $2 \mathrm{i}$ conditions, which suggests an inherent termination mechanism (Fig EV5A). 
Analysis of Pol II mutants revealed that mutants with slower elongation velocity also exhibited a shorter termination window (Hazelbaker et al, 2013; Sheridan et al, 2019). To which extent the natural elongation velocity explains termination read-through has not been determined. Therefore, we analysed TT-seq nascent RNA coverage in a $15 \mathrm{~kb}$ termination window across groups of genes with increasing elongation velocity and found that indeed fast elongation genes had longer read-through distances (Fig 5D).

We wondered if elongation velocity was the dominant determinant of read-through distance. To this end, we calculated the average velocity in the read-through window of each gene and evaluated the extent of which elongation velocity versus a large panel of known epigenomic features can explain the read-through distance. We first assumed linear responses and ranked with Pearson's correlation. The long read-through distances (>9 kb) associated with the faster estimated read-through/gene body velocity, higher H3K36me3 and gene lengths. In contrast short read-through $(<3 \mathrm{~kb})$ windows associated with $\mathrm{H} 3.3$, Chd8, Chd1 enrichment and GC content in the termination window (Fig 5B). A total of $25 \%$ read-through distance variance could be explained by a multivariate linear model, in which the estimated read-through velocity explained the largest variance of read-through distance (Fig 5C). We further confirmed readthrough velocity's importance with a gradient boosting machine (gbm) nonlinear model, which explained $56 \%$ variance with acceptable prediction accuracy of the read-through distances (Fig EV5C-E). At the ultimate termination sites (-1 kb, 1kb ) windows, we also found co-localization of 
chromatin accessibility and daRNA initiation, which suggest antisense transcription collision may participate in the termination process for a small number of cases (Fig EV5B).

\section{Attenuated elongation velocity associates with shorter read-through distance.}

By our estimated termination sites, slower elongation in 2i/mTORi coincided with shorter median read-through distances: SL $5.1 \mathrm{~kb}, 2 \mathrm{i} 4.6 \mathrm{~kb}$ and mTORi $3.9 \mathrm{~kb}$ (Fig 5F). Termination sites in 2i and mTORi cells were mainly located within $5 \mathrm{~kb}$ downstream of the transcript end site (TES) (Fig 5F). In line with this, the estimated elongation velocity rapidly declined in $2 \mathrm{i} / \mathrm{mTORi}$ cells within $5 \mathrm{~kb}$ after the TES, while in SL condition median estimated elongation velocity decreased more gradually (Fig $5 \mathrm{E}$ ). We noted that the steepest decline in elongation velocity immediately preceded the ultimate termination site (Fig 5F). Thus, our data supports a model in which Pol II encounters termination roadblocks imposed by DNA sequence, and the remaining velocity at the encounter stochastically determines if the polymerase comes to a complete stop.

To understand if altered elongation velocity in $2 \mathrm{i}$ and $\mathrm{mTORi}$ conditions also affected termination read-through distance, we grouped genes according to their read-through distance shortening, extending or remaining unchanged with \pm 500 bp (Fig 5G-J). Genes with an extended read-through distance in $2 \mathrm{i}$ or mTORi were not associated with a clear extension of the average TT-seq nascent signal and represented sporadic cases where relatively low labeled RNA read coverage may have prohibited accurate termination site determination (Fig $5 \mathrm{H}$ ). Genes with a shortened read- 
through distance in $2 \mathrm{i}$ or mTORi also exhibited a marked drop in RNA synthesis, where labeled RNA coverage reached a baseline several kb earlier (Fig 5I).

We extracted the GC nucleotide frequency around the termination sites for the three different groups. Irrespective if the termination shifted to an earlier or later site, both the old and new termination sites exhibited a sharp local maximum in G/C-richness (Fig 5I-J). This recapitulated the G/C-rich motif mapped at K562 cells termination sites (Schwalb et al, 2016). Therefore, switching pluripotent conditions, the main termination of genes either remained centered on the same G/C-rich sequence motif, or switched to an earlier or later G/C-rich sequence motif. In the model described above, G/C-rich motifs thus provide roadblocks to RNA polymerase II that lead to a final termination if the velocity is already sufficiently reduced.

\section{Discussion}

With the assistance of quantitative techniques, our data uncovers global transcriptional features distinguishing related pluripotent states of mouse embryonic stem cells. Our data supports a model in which inhibition of MAPK/GSK3b or mTOR signaling pathways by $2 \mathrm{i}$ or mTORi, respectively, directly affect global transcriptional output and RNA polymerase elongation dynamics without proportional changes in chromatin features known to associate with proteincoding gene transcription initiation or elongation. 
Of note, inhibition of mTOR signaling homogeneously reduced RNA synthesis rates to a large extent and only marginally redistributed transcriptional activity on both coding and non-coding TUs (Fig 1B-C; Fig EV2C). In contrast, the SL-to-2i transition leads to a larger rewiring of mRNA gene expression. Intriguingly, transcriptional changes occur mostly without changes in enhancerpromoter interactions (Atlasi et al, 2019; McLaughlin et al, 2019), suggesting that enhancerpromoter pairing provides hardwired connectivity that remains responsive to cellular signaling (Schoenfelder \& Fraser, 2019). 2i-specific enhancer activation occurs via the loading of Esrrb upon the pre-existing chromatin interactions (Atlasi et al, 2019), resulting in H3K27ac enrichment (Schoenfelder \& Fraser, 2019; Barakat et al, 2018), which itself appears characteristic albeit not necessary for enhancer function (Zhang et al, 2020; Sanchez et al, 2018). In our data, intergenic ncRNAs showed a strand and distance dependent co-regulation with neighboring coding genes, which was associated with enhancer potentials in $2 \mathrm{i}$ cells but not in mTORi cells (Fig 2E). The global rewiring of cell signaling and metabolism in the ground state, therefore, reveals the large extent of co-regulation of ncRNAs with their adjacent genes (Engreitz et al, 2016) (Fig 2F, Fig EV2H). Spurious transcription, such as bidirectional intergenic TUs without enhancer annotation or active chromatin states do not follow the global transcriptional repression in $2 \mathrm{i}$ (Fig $2 \mathrm{C}$ ), which may be an effect of the global CpG hypermethylation observed in 2i (Jin et al, 2017; Haberle \& Stark, 2018; Walter et al, 2016).

Previous estimates of transcription elongation kinetics rely on chemical inhibition and time-series experiments, either by transcription release after the inhibitor clearance (Danko et al, 2013; 
Fuchs et al, 2014; Veloso et al, 2014), Pol II initiation/pause-release repression (Jonkers et al, 2014) or RNA reporter elongation efficacy (Fukaya et al, 2017). Such velocity estimations still leave details of global and local elongation dynamics unaddressed (Jonkers \& Lis, 2015). Furthermore, it has been shown that with a multi-omics approach, which combines TT-seq with mNET-seq derived Pol II occupancies, transcription elongation velocities can be estimated (Caizzi et al, 2021). Accordingly, we used here the ratio of TT-seq nascent RNA and Pol II S5p coverage as an approximation of elongation velocity and show that it provides a universal and transcriptome-wide measurement of several key parameters: First, we were able to estimate the unperturbed elongation velocity coverage continuously from initiation to termination (Fig EV3C). Second, we were able to compare native elongation velocity across different cell states (Fig 3C). Third, we deduced the relationship of elongation velocity, RNA synthesis and Pol II occupancy, which supports the observation that elongation velocity has a minimal impact on RNA synthesis (Jonkers et al, 2014). Fourth, we mapped the local transcription dynamics downstream of the TSS and in the termination window, and recapitulated the relationships of pausing/elongation duration and elongation velocity/read-through distance. Although low gene expression impedes local velocity estimation from TT-seq nascent RNA and Pol II coverages, a TU-level velocity estimation, averaging TT-seq signal on the entire TU, provides a reliable comparison across conditions. Therefore we were able to deduce that RNA synthesis decrease in the pluripotent state transitions is independent from elongation slowdown and neither controlled by pause release dynamics (Fig 3L, Fig EV3B). This result agrees with a recent study that transcription 
initiation dominates gene regulation in murine erythropoiesis differentiation over pause-release dynamics (Larke et al, 2021).

Finally, elongation velocity explains the termination read-though length more than any other chromatin feature, although the ultimate elongation slow-down may manifest Pol II disassembly by the RNA cleavage-mediated "torpedo" model (West et al, 2004; Brannan et al, 2012; Nojima et al, 2015; Baejen et al, 2017) (Fig EV5B). Given the read-through distances were well preserved across sequencing methods (Fig EV5A), we can conclude that slower elongation in $2 \mathrm{i}$ and mTORi conditions brought only a fraction of genes to earlier termination with the majority of readthrough distances inherently unchanged (Fig 5J, Fig EV5A). A higher frequency of read-through window shortening was observed in in mTORi cells. but the exact changes of termination window length are gene-specific and may depend on GC-rich motif occurrence in the termination window (Fig EV6A-B, Fig 5I). Nevertheless, the large overlap of genes with shorter read-through in $2 \mathrm{i}$ and mTORi cells reveals the subgroup of genes that are responsive to elongation velocity slowdown (Fig 5I-J). Therefore, at the cell population level, multiple termination sites may exist simultaneously, among which our method detects the most frequent site in use (Fig 5B). Elongation velocity reduces relatively quickly upon passing the TES (Fig 4D) but continues to traverse at a slower level until the final termination site. Thus, read-through velocity has a more direct influence on the termination site usage as compared to other chromatin features (Fig 5F).

In sum, our findings reveal transcription dynamic changes in the pluripotent states, and suggest the decisive role of RNA synthesis in regulation of coding and non-coding RNAs cellular 
abundance. Our analysis of elongation velocity with the multi-omics strategy provides new insights into promoter-proximal pausing and termination read-through in mouse ES cells.

\section{Materials and Methods}

Cell culture. Mouse embryonic stem cell RW4 (male, 129X1/SvJ) were cultured 0.1\% gelatincoated dishes with serum medium: Knock-out DMEM medium with 15\% FBS (Sigma, F7524), 0.1mM ESGRO LIF (Sigma, ESG1107), 2 mM GlutaMAX (ThermoFisher, 10565018), 0.1 mM NonEssential Amino Acid (Sigma, M7145), 0.1 mM $\beta$-mercaptoethanol (Sigma, M3148); 2i medium: ESGRO Complete Basal Medium (Millipore, SF002), $3 \mu \mathrm{M}$ GSK3 $\beta$ inhibitor CHIR99021 (Sigma, SML1046), 1 M Mek 1/2 inhibitor PD0325901 (Sigma, PZ0162), 0.1 mM LIF. Inhibition of mTOR was in serum-LIF (SL) medium supplemented with 200nM INK128 (CAYM11811-1).

TT-seq extraction protocol. TT-seq labeling steps were performed as described before (Gressel et al, 2019; Schwalb et al, 2016) with minor modifications. In short, cells in the different pluripotent media were cultured for 1-2 days in four $15 \mathrm{~cm}$ dishes. With one dish for cell number counting, and the rest were supplemented with $500 \mu \mathrm{M}$ of 4-thiouridine (4sU) (Sigma-Aldrich, T4509) for $5 \mathrm{~min}$ at $37^{\circ} \mathrm{C}$ and $5 \% \mathrm{CO} 2$, then immediately quenched by adding TRIzol (ThermoFisher, 15596018) for RNA extraction. Total RNA was fragmented to $1 \mathrm{~kb}$ with Bioruptor (Diagenode), then coupled with HPDP-Biotin (ThermoFisher, 21341) dissolved in 
dimethylformamide (VWR, 1.02937.0500). A small aliquot was saved as fragmented total RNA (FRNA) and the rest was purified with $\mu$ MACS streptavidin beads (Miltenyi Biotec, 130-074-101). Purified labeled RNA (LRNA) and FRNA were subjected to DNase digestion (Qiagen, 79254). Total fragmented RNA and labeled RNA libraries were prepared with Ovation Universal RNA-Seq kit (NUGEN, 79254). The pooled library was size-selected by Ampure XP beads (Beckman Coulter, A63881) before sequencing with NextSeq ${ }^{\circledR}$ 500/550 High Output Kit v2 (Illumina, FC-404-2005, 75 cycles).

Reads alignment and TU annotation. Paired-end short reads were aligned to $\mathrm{mm} 9$ and $\mathrm{mm} 10$ genome references (GENCODE) by STAR 2.7.3a with setting:

--outFilterMismatchNoverReadLmax 0.02 --outFilterMultimapScoreRange 0 --alignEndsType EndToEnd.

Mapped reads were subjected to transcription unit annotation as described before (Schwalb et al, 2016), processed in parallel by "TU filter" (R shiny app). Briefly, paired-end reads mid-points were binned into 200 bp genome coverage matrices by strand (merging the counts if sample has multiple replicates), then subjected to the binary hidden Markov state calling with $\mathrm{R}$ package "GenoSTAN" with "PoissonLog" method. Next the active state intervals were as the raw TUs and joined by exons per gene. Non-coding TU locations were named by their relative position to the nearby coding TUs (Fig EV2A). 
TU differential expression analysis was performed by DESeq2 (1.24.0) (Love et al, 2014) with read counts on the annotated TU intervals by featureCounts (Rsubread 1.34.7) (Liao et al, 2019).

Spike-in RNA design. ERCC synthetic spike-in RNAs were used as external reference for total RNA and labeled RNA sample size normalization as described in (Gressel et al, 2019; Schwalb et al, 2016) with minor modifications. Briefly, 6 pairs of spike-in RNAs with 4sU labeled/unlabeled mixture were prepared as below:

\begin{tabular}{lll}
\hline ERCC spike-in RNA & Concentration $(\mathrm{ng} / \mu \mathrm{L})$ & $\begin{array}{l}\text { Labeled rate } \\
(\%)\end{array}$ \\
\hline Sp2 (ERCC-00043) & 1 & 100 \\
Sp4 (ERCC-00136) & 0.1 & 100 \\
Sp5 (ERCC-00145) & 1 & 10 \\
Sp8 (ERCC-00092) & 0.1 & 10 \\
Sp9 (ERCC-00002) & 1 & 0 \\
Sp12 (ERCC-00170) & 0.1 & 0 \\
\hline
\end{tabular}

For every million cells, 0.4 ng spike-in mix was added into the TRIzol (ThermoFisher, 15596018) cell lysis to eliminate technical errors retained during the steps of biotinylating, RNA purification and library preparation. 
Sample size estimation. We quantified GENCODE transcripts, de novo annotated TUs and spikein transcripts using the alignment-free mapper (kallisto 0.46.2). For normalization, we calculated the size factors of all spike-ins in the total transcriptome and spike-ins $2-8$ in the labeled transcriptome according to DESeq's method (Love et al, 2014). The normalised transcriptomes were subjected to size factor calculation again and presented as the relative sample sizes of both total and labeled RNA abundance (Fig 1E).

RNA synthesis rate estimation. The estimated labeled/total RNA read counts of GENCODE transcripts and spike-ins from kallisto were first normalized by respective spike-ins sizes from each sample. The highest expressed transcript of each gene was kept. A linear model was trained only with the normalized labeled spike-ins (Sp2, Sp4, Sp5 and Sp8) log2 labeled ( $\left.\mathrm{X}_{\mathrm{L}}\right)$ and total $\left(\mathrm{X}_{\mathrm{F}}\right)$ read counts in response to the respective label rates $r$ : $\log _{2}(r) \sim X_{F}+X_{L}$. The evaluation was performed with 5 -fold cross validation with 10 times subsampling, and the predictions on the hold-on set were examined. Then a final model with spike-ins counts of all samples were trained, which resulted in an adjusted $\mathrm{R}$-squared 0.9917 . And labeled rate prediction was made with transcript's labeled/total read counts. In the same way, a second model was trained to predict all spike-ins weight per cell $w: \log 2(w) \sim X_{F}+X_{L}$, which resulted in an adjusted R-squared 0.991. Then the copy number per cell was transformed from weight with transcript effective length from kallisto. Finally, RNA synthesis rate $\left(\right.$ cell $^{-1}$ minute $^{-1}$, or copy/min per cell) was calculated by multiplying labeled rate and transcript copy number. 
Read coverage. Short reads genome coverage was processed with R/Bioconductor packages "rtracklayer" and "rsamtools" by piling up only the uniquely mapped and paired-end reads with insertion size less than $2 \mathrm{~kb}$. Sample-wise coverage of each genomic interval was normalized by the respective size factors. For TT-seq sample size factors were generated from spike-in RNA read counts, for MINUTE-ChIP samples scaling factors were from the respective input sizes. In the heatmaps and coverage profile plots, each coverage vector of different lengths was resized by "spline" function to the same number of positions.

Pol I, Pol II and Pol III TU classification. RNA polymerases ChIP-seq datasets ( (Jiang et al, 2020), GSE145791) were aligned to mm10 genome by bowtie2 with “--local” setting. Each TU's Pol I, Pol II and Pol III density were divided by the sum to obtain relative occupancies, and a threshold of 90\% enrichment was used for the classification indicated in the ternary plot (Fig EV1H). For validation, ChIP-seq data of Pol III subunits PRC1, PRC4 and the cofactors BRF1, TFIII ((Carrière et al, 2012), E-MTAB-767) were aligned and subjected to peak calling with MACS2 default setting at "-q 0.01" cutoff, and overlapped on the ternary plot of the combined intergenic TUs (GRO-seq, PRO-seq and TT-seq).

Epigenome feature extraction. Promoter DNA sequences were extracted around the TSS (-1000 nt to $+50 \mathrm{nt}$ ) on the sense strand. CpG number was by CG dinucleotide, TATA number was by the "TATA" pattern. For counting ChIP-seq signal density, TSS intervals (-500 bp to $500 \mathrm{bp}$ ) and Ensembl (GRCm38.79) gene body intervals were used, with the samples as below:

\begin{tabular}{llll}
\hline Features & Types & Gene Parts & Catalogue Reference
\end{tabular}




\begin{tabular}{|c|c|c|c|c|}
\hline TSS DNAme. & DNA & TSS & GSM1127953 & (Galonska et al, 2015) \\
\hline GB DNAme. & DNA & Gene body & GSM1127953 & (Galonska et al, 2015) \\
\hline DHS & DNA & TSS & GSM1014154 & (Vierstra et al, 2014) \\
\hline E2f1 & General TF & TSS & GSM288349 & (Chen et al, 2008) \\
\hline TBP & General TF & TSS & GSM1816104 & (Langer et al, 2016) \\
\hline TFIID & General TF & TSS & GSM958503 & (Ku et al, 2012) \\
\hline Sp1 & General TF & TSS & GSM3258754 & (Hartl et al, 2019) \\
\hline Aff4 & General TF & Gene body & GSM749810 & (Lin et al, 2011) \\
\hline cMyc & Pluripotent TF & TSS & GSM2417145 & (Chronis et al, 2017) \\
\hline Esrrb & Pluripotent TF & TSS & GSM2417188 & (Chronis et al, 2017) \\
\hline Klf4 & Pluripotent TF & TSS & GSM2417144 & (Chronis et al, 2017) \\
\hline Nanog & Pluripotent TF & TSS & GSM2417187 & (Chronis et al, 2017) \\
\hline Oct4 & Pluripotent TF & TSS & GSM2417142 & (Chronis et al, 2017) \\
\hline Sox 2 & Pluripotent TF & TSS & GSM2417143 & (Chronis et al, 2017) \\
\hline CTCF & Enhancer Activity & TSS & GSM3615255 & (Atlasi et al, 2019) \\
\hline p300 & Enhancer Activity & TSS & GSM2417169 & (Chronis et al, 2017) \\
\hline Hdac1 & Enhancer Activity & TSS & GSM2417173 & (Chronis et al, 2017) \\
\hline Med1 & Enhancer Activity & TSS & GSM3084070 & (Sabari et al, 2018) \\
\hline Brd4 & Enhancer Activity & TSS & GSM3084073 & (Sabari et al, 2018) \\
\hline Yy1 & Enhancer Activity & Gene body & GSM2645362 & (Weintraub et al, 2017) \\
\hline Chd1 & Remodeler & Gene body & GSM1581288 & (de Dieuleveult et al, 2016) \\
\hline Chd2 & Remodeler & Gene body & GSM1581290 & (de Dieuleveult et al, 2016) \\
\hline Chd9 & Remodeler & Gene body & GSM1581298 & (de Dieuleveult et al, 2016) \\
\hline HP1a & Domain & Gene body & GSM2582363 & (Ostapcuk et al, 2018) \\
\hline Lamin B & Domain & Gene body & GSM2579539 & (Poleshko et al, 2017) \\
\hline $\mathrm{H} 2 \mathrm{AZ}$ & Histone & Gene body & GSM1287699 & (Surface et al, 2016) \\
\hline $\mathrm{H} 2 \mathrm{AX}$ & Histone & Gene body & GSM1847704 & (Wu et al, 2016) \\
\hline H33 YFP & Histone & Gene body & GSM2582412 & (Chen et al, 2018) \\
\hline $\mathrm{H} 2 \mathrm{BK} 20 \mathrm{ac}$ & Acetylation & Gene body & GSM1874093 & (Kumar et al, 2016) \\
\hline H3K9ac & Acetylation & Gene body & GSM2417092 & (Chronis et al, 2017) \\
\hline H3K27ac & Acetylation & Gene body & GSM2417096 & (Chronis et al, 2017) \\
\hline H3К56ас & Acetylation & Gene body & GSM3747805 & (Etchegaray et al, 2019) \\
\hline
\end{tabular}




$\begin{array}{lllll}\text { H3K64ac } & \text { Acetylation } & \text { Gene body } & \text { GSM3143869 } & \text { (Martire et al, 2019) } \\ \text { H3K122ac } & \text { Acetylation } & \text { Gene body } & \text { GSM3143871 } & \text { (Martire et al, 2019) } \\ \text { H3K4me1 } & \text { Methylation } & \text { Gene body } & \text { GSM2417088 } & \text { (Chronis et al, 2017) } \\ \text { H3K4me3 } & \text { Methylation } & \text { TSS } & \text { GSM2417080 } & \text { (Chronis et al, 2017) } \\ \text { H3K9me3 } & \text { Methylation } & \text { Gene body } & \text { GSM2417112 } & \text { (Chronis et al, 2017) } \\ \text { H3K27me3 } & \text { Methylation } & \text { Gene body } & \text { GSM2417100 } & \text { (Chronis et al, 2017) } \\ \text { H3K36me2 } & \text { Methylation } & \text { Gene body } & \text { GSM3772688 } & \text { (Weinberg et al, 2019) } \\ \text { H3K36me3 } & \text { Methylation } & \text { Gene body } & \text { GSM2417108 } & \text { (Chronis et al, 2017) } \\ \text { H3K79me2 } & \text { Methylation } & \text { Gene body } & \text { GSM2417104 } & \text { (Chronis et al, 2017) } \\ \text { H2AUb } & \text { Ubiquitination } & \text { Gene body } & \text { GSM2393583 } & \text { (Kundu et al, 2017) } \\ \text { H2AK119ub1 } & \text { Ubiquitination } & \text { Gene body } & \text { GSM2865672 } & \text { (Yao et al, 2018) }\end{array}$

Log1p transformed ChIP densities were trimmed at 99.5\% quantile to remove technical outliers, and standardized to normal distribution $\mathrm{N}(0,1)$. Each feature explaining a particular response (e.g. read-through distance, Fig 5F) was decomposed for $R^{2}$, by a multivariate linear regression through the origin.

Pol II pausing index. Pol II TSS pausing intervals were generated from the closest 5' capped RNA peaks (Start-seq (Dorighi et al, 2017), GSM2586572). Start-seq reads were aligned by STAR 2.7.3a and called peaks by HOMER 4.11 (Heinz et al.) with the following setting: findPeaks -style groseq -size 20 -fragLength 20 -inputFragLength 40 -tssSize 5 -minBodySize 30 -pseudoCount 1. Pausing intervals of the active gene were assigned by the closest non-redundant capped RNA intervals, which were used for TSS peak density calculation. Pol II S5p MINUTE-ChIP bigwig coverages, processed as described before (Kumar \& Elsässer, 2019), were subjected to gene body density extraction from (TSS+500 to TSS $+1500 \mathrm{bp}$ ) interval. The resulting ratios were used as the pausing index (Fig 3F). 
Transcription elongation velocity estimation. The time course Cdk9 inhibition GRO-seq samples (Jonkers et al, 2014) were annotated by TU filter to capture ongoing transcription events. The current travel distance from gene TSS were retrieved by the nearest TU fragment annotation, and were subjected to a linear regression model in response to Cdk9 inhibition times where the slope coefficient represented reversed elongation velocity and the intersection term adjusted for response time delay. The resulting elongation velocities for 3703 genes were used as the "measured elongation velocity" for cross-validation. Elongation velocities v can also be estimated from the ratio of the number of polymerases released into elongation, as measured by TT-seq, over the Pol II occupancy (Gressel et al, 2019; Caizzi et al, 2021). Thus, to derive "estimated elongation velocity" from our multi-omics data we combined TT-seq LRNA coverage with Pol II S5p MINUTE ChIP-seq coverage as follows:

$$
\hat{v} \approx \frac{R P K_{T T-s e q L R N A}}{R P K_{\text {PolIIS5p }}}
$$

This approximation allows relative comparison between different conditions as long as the numerator and denominator terms, TT-Seq and Pol II S5p signals are quantitative. To this end, TT-Seq normalization by external spike-ins is performed as described above, and MINUTE-ChIP quantitative scaling is carried out as described (Kumar \& Elsässer, 2019).

Calling termination sites. For the $15 \mathrm{~kb}$ genome interval extending from the last exons of each gene, TT-seq LRNA reads coverage was piled up with the first paired read, log transformed and binned with $75 \mathrm{bp}$ interval. To capture the significant decline of RNA synthesis after transcription passing the ultimate termination site, we slided the position that gave the maximum contrast of 
labeled RNA densities before and after that site. In practice, TT-seq nascent RNA read coverage in the termination window was scaled $($ mean $=0$ ) and their cumulative sums from the beginning to the end of the termination window were calculated. The maximum position was defined as the ultimate termination site (Fig 5A).

Non-linear model prediction of read-through distance. We used a tree-based gradient boosting model (gbm, R package) to evaluate the non-linear response of read-through distance with 41 chromatin features. The model training control was 10 -fold cross validation, and with the tuned depth 40 and 1000 trees under 0.1 shrinkage. Test set was split by the ratio 0.2 of total cases $(n=8348)$. The trained model of predicting numerical read-through distance was applied to the test set, and compared to the actual read-through lengths (Fig EV5D). Feature importance was extracted from this model as complement to the R-squared linear explanation (Fig 5C). We evaluated gbm performance with binned read-through groups $(3,5,8,15 \mathrm{~kb})$ and ROC curves were then plotted to evaluate the model performance (Fig EV5E). 


\section{Data availability}

Primary and processed data generated for this study has been submitted to the Gene Expression

Omnibus under GSE168378 (TT-seq) and GSE126252 (MINUTE-ChIP).

\section{Code availability}

Transcription unit annotation R shiny app local workflow can be found on GitHub

https://github.com/shaorray/TU filter. Data analysis steps are also available on

Github: https://github.com/shaorray/TT-seq mESC pluripotency.

\section{ACKNOWLEDGEMENTS}

Bioinformatics analyses were performed on resources provided by the Swedish National Infrastructure for Computing (SNIC) at Uppmax server (projects SNIC 2020/15-9, SNIC 2020/6-3, uppstore2018208, SNIC 2018/3-669, sllstore2017057, SNIC 2017/1-508). We thank members of the Elsässer lab for comments and help with experiments and analysis. S.J.E acknowledges funding by the Karolinska Institutet SFO for Molecular Biosciences, Vetenskapsrådet (201504815, 2020-04313), H2020 ERC Starting Grant (715024 RAPID), Åke Wibergs Stiftelse (M150275), Cancerfonden (2015/430). R.S. acknowledges funding from the Chinese Scholarship Council.

\section{AUTHOR CONTRIBUTIONS}


R.S. and S.J.E. conceived study. R.S. performed TT-seq and B.K. performed MINUTE-ChIP

experiments. R.S. analyzed all data. K.F., M.L. and P.C advised on TT-seq. R.S. generated figures.

R.S. and S.J.E. wrote the manuscript with input from all authors.

\section{COMPETING INTEREST}

The authors declare no competing interests.

\section{REFERENCES}

Andersson R, Gebhard C, Miguel-Escalada I, Hoof I, Bornholdt J, Boyd M, Chen Y, Zhao X, Schmidl C, Suzuki T, Ntini E, Arner E, Valen E, Li K, Schwarzfischer L, Glatz D, Raithel J, Lilje B, Rapin N, Bagger FO, et al (2014) An atlas of active enhancers across human cell types and tissues. Nature 507: 455-461

Ardehali MB, Anselmo A, Cochrane JC, Kundu S, Sadreyev RI \& Kingston RE (2017) Polycomb repressive complex 2 methylates elongin A to regulate transcription. Mol. Cell 68: 872884.e6

Atlasi Y, Megchelenbrink W, Peng T, Habibi E, Joshi O, Wang S-Y, Wang C, Logie C, Poser I, Marks H \& Stunnenberg HG (2019) Epigenetic modulation of a hardwired 3D chromatin landscape in two naive states of pluripotency. Nat. Cell Biol. 21: 568-578

Atlasi Y \& Stunnenberg HG (2017) The interplay of epigenetic marks during stem cell differentiation and development. Nat. Rev. Genet. 18: 643-658

Baejen C, Andreani J, Torkler P, Battaglia S, Schwalb B, Lidschreiber M, Maier KC, Boltendahl A, Rus P, Esslinger S, Söding J \& Cramer P (2017) Genome-wide Analysis of RNA Polymerase II Termination at Protein-Coding Genes. Mol. Cell 66: 38-49.e6

Barakat TS, Halbritter F, Zhang M, Rendeiro AF, Perenthaler E, Bock C \& Chambers I (2018) Functional dissection of the enhancer repertoire in human embryonic stem cells. Cell Stem Cell 23: 276-288.e8

Bartman CR, Hamagami N, Keller CA, Giardine B, Hardison RC, Blobel GA \& Raj A (2019) Transcriptional burst initiation and polymerase pause release are key control points of 
transcriptional regulation. Mol. Cell 73: 519-532.e4

Benabdallah NS, Williamson I, Illingworth RS, Kane L, Boyle S, Sengupta D, Grimes GR, Therizols

P \& Bickmore WA (2019) Decreased Enhancer-Promoter Proximity Accompanying

Enhancer Activation. Mol. Cell 76: 473-484.e7

Brannan K, Kim H, Erickson B, Glover-Cutter K, Kim S, Fong N, Kiemele L, Hansen K, Davis R, Lykke-Andersen J \& Bentley DL (2012) mRNA decapping factors and the exonuclease Xrn2 function in widespread premature termination of RNA polymerase II transcription. Mol. Cell 46: 311-324

Brown DA, Di Cerbo V, Feldmann A, Ahn J, Ito S, Blackledge NP, Nakayama M, McClellan M, Dimitrova E, Turberfield AH, Long HK, King HW, Kriaucionis S, Schermelleh L, Kutateladze TG, Koseki H \& Klose RJ (2017) The SET1 Complex Selects Actively Transcribed Target Genes via Multivalent Interaction with CpG Island Chromatin. Cell Rep. 20: 2313-2327

Buettner F, Natarajan KN, Casale FP, Proserpio V, Scialdone A, Theis FJ, Teichmann SA, Marioni JC \& Stegle O (2015) Computational analysis of cell-to-cell heterogeneity in single-cell RNAsequencing data reveals hidden subpopulations of cells. Nat. Biotechnol. 33: 155-160

Bulut-Karslioglu A, Biechele S, Jin H, Macrae TA, Hejna M, Gertsenstein M, Song JS \& RamalhoSantos M (2016) Inhibition of mTOR induces a paused pluripotent state. Nature 540: 119123

Caizzi L, Monteiro-Martins S, Schwalb B, Lysakovskaia K, Schmitzova J, Sawicka A, Chen Y, Lidschreiber M \& Cramer P (2021) Efficient RNA polymerase II pause release requires U2 snRNP function. Mol. Cell 81: 1920-1934.e9

Carrière L, Graziani S, Alibert O, Ghavi-Helm Y, Boussouar F, Humbertclaude H, Jounier S, Aude J-C, Keime C, Murvai J, Foglio M, Gut M, Gut I, Lathrop M, Soutourina J, Gérard M \& Werner M (2012) Genomic binding of Pol III transcription machinery and relationship with TFIIS transcription factor distribution in mouse embryonic stem cells. Nucleic Acids Res. 40: 270-283

Chen CCL, Goyal P, Karimi MM, Abildgaard MH, Kimura H \& Lorincz MC (2018) H3S10ph broadly marks early-replicating domains in interphase ESCs and shows reciprocal antagonism with H3K9me2. Genome Res. 28: 37-51

Chen X, Xu H, Yuan P, Fang F, Huss M, Vega VB, Wong E, Orlov YL, Zhang W, Jiang J, Loh Y-H, Yeo HC, Yeo ZX, Narang V, Govindarajan KR, Leong B, Shahab A, Ruan Y, Bourque G, Sung W-K, et al (2008) Integration of external signaling pathways with the core transcriptional network in embryonic stem cells. Cell 133: 1106-1117

Chronis C, Fiziev P, Papp B, Butz S, Bonora G, Sabri S, Ernst J \& Plath K (2017) Cooperative binding of transcription factors orchestrates reprogramming. Cell 168: 442-459.e20 
Danko CG, Hah N, Luo X, Martins AL, Core L, Lis JT, Siepel A \& Kraus WL (2013) Signaling pathways differentially affect RNA polymerase II initiation, pausing, and elongation rate in cells. Mol. Cell 50: 212-222

de Dieuleveult M, Yen K, Hmitou I, Depaux A, Boussouar F, Bou Dargham D, Jounier S, Humbertclaude H, Ribierre F, Baulard C, Farrell NP, Park B, Keime C, Carrière L, Berlivet $S$, Gut M, Gut I, Werner M, Deleuze J-F, Olaso R, et al (2016) Genome-wide nucleosome specificity and function of chromatin remodellers in ES cells. Nature 530: 113-116

Dorighi KM, Swigut T, Henriques T, Bhanu NV, Scruggs BS, Nady N, Still CD, Garcia BA, Adelman K \& Wysocka J (2017) MII3 and MII4 Facilitate Enhancer RNA Synthesis and Transcription from Promoters Independently of H3K4 Monomethylation. Mol. Cell 66: 568-576.e4

Efroni S, Duttagupta R, Cheng J, Dehghani H, Hoeppner DJ, Dash C, Bazett-Jones DP, Le Grice S, McKay RDG, Buetow KH, Gingeras TR, Misteli T \& Meshorer E (2008) Global transcription in pluripotent embryonic stem cells. Cell Stem Cell 2: 437-447

Ehrensberger AH, Kelly GP \& Svejstrup JQ (2013) Mechanistic interpretation of promoterproximal peaks and RNAPII density maps. Cell 154: 713-715

Engreitz JM, Haines JE, Perez EM, Munson G, Chen J, Kane M, McDonel PE, Guttman M \& Lander ES (2016) Local regulation of gene expression by IncRNA promoters, transcription and splicing. Nature 539: 452-455

Etchegaray J-P, Zhong L, Li C, Henriques T, Ablondi E, Nakadai T, Van Rechem C, Ferrer C, Ross KN, Choi J-E, Samarakkody A, Ji F, Chang A, Sadreyev RI, Ramaswamy S, Nechaev S, Whetstine JR, Roeder RG, Adelman K, Goren A, et al (2019) The Histone Deacetylase SIRT6 Restrains Transcription Elongation via Promoter-Proximal Pausing. Mol. Cell 75: 683699.e7

Farnung L, Ochmann M, Engeholm M \& Cramer P (2021) Structural basis of nucleosome transcription mediated by Chd1 and FACT. Nat. Struct. Mol. Biol.

Flynn RA, Do BT, Rubin AJ, Calo E, Lee B, Kuchelmeister H, Rale M, Chu C, Kool ET, Wysocka J, Khavari PA \& Chang HY (2016) 7SK-BAF axis controls pervasive transcription at enhancers. Nat. Struct. Mol. Biol. 23: 231-238

Frankish A, Diekhans M, Jungreis I, Lagarde J, Loveland JE, Mudge JM, Sisu C, Wright JC, Armstrong J, Barnes I, Berry A, Bignell A, Boix C, Carbonell Sala S, Cunningham F, Di Domenico T, Donaldson S, Fiddes IT, García Girón C, Gonzalez JM, et al (2021) GENCODE 2021. Nucleic Acids Res. 49: D916-D923

Fuchs G, Voichek Y, Benjamin S, Gilad S, Amit I \& Oren M (2014) 4sUDRB-seq: measuring genomewide transcriptional elongation rates and initiation frequencies within cells. Genome Biol. 15: R69 
Fukaya T, Lim B \& Levine M (2017) Rapid rates of pol II elongation in the drosophila embryo. Curr. Biol. 27: 1387-1391

Galonska C, Ziller MJ, Karnik R \& Meissner A (2015) Ground State Conditions Induce Rapid Reorganization of Core Pluripotency Factor Binding before Global Epigenetic Reprogramming. Cell Stem Cell 17: 462-470

Ghimire S, Van der Jeught M, Neupane J, Roost MS, Anckaert J, Popovic M, Van Nieuwerburgh F, Mestdagh P, Vandesompele J, Deforce D, Menten B, Chuva de Sousa Lopes S, De Sutter P \& Heindryckx B (2018) Comparative analysis of naive, primed and ground state pluripotency in mouse embryonic stem cells originating from the same genetic background. Sci. Rep. 8: 5884

Glover-Cutter K, Larochelle S, Erickson B, Zhang C, Shokat K, Fisher RP \& Bentley DL (2009) TFIIH-associated Cdk7 kinase functions in phosphorylation of C-terminal domain Ser7 residues, promoter-proximal pausing, and termination by RNA polymerase II. Mol. Cell. Biol. 29: 5455-5464

Gressel S, Schwalb B \& Cramer P (2019) The pause-initiation limit restricts transcription activation in human cells. Nat. Commun. 10: 3603

Gressel S, Schwalb B, Decker TM, Qin W \& Elife HL CDK9-dependent RNA polymerase II pausing controls transcription initiation. cdn.elifesciences.org

Haberle V \& Stark A (2018) Eukaryotic core promoters and the functional basis of transcription initiation. Nat. Rev. Mol. Cell Biol. 19: 621-637

Hartl D, Krebs AR, Grand RS, Baubec T, Isbel L, Wirbelauer C, Burger L \& Schübeler D (2019) CG dinucleotides enhance promoter activity independent of DNA methylation. Genome Res. 29: 554-563

Hazelbaker DZ, Marquardt S, Wlotzka W \& Buratowski S (2013) Kinetic competition between RNA Polymerase II and Sen1-dependent transcription termination. Mol. Cell 49: 55-66

Herzog VA, Reichholf B, Neumann T, Rescheneder P, Bhat P, Burkard TR, Wlotzka W, von Haeseler A, Zuber J \& Ameres SL (2017) Thiol-linked alkylation of RNA to assess expression dynamics. Nat. Methods 14: 1198-1204

Jiang Y, Huang J, Lun K, Li B, Zheng H, Li Y, Zhou R, Duan W, Wang C, Feng Y, Yao H, Li C \& Ji X (2020) Genome-wide analyses of chromatin interactions after the loss of Pol I, Pol II, and Pol III. Genome Biol. 21: 158

Jin Y, Eser U, Struhl K \& Churchman LS (2017) The ground state and evolution of promoter region directionality. Cell 170: 889-898.e10

Jonkers I, Kwak H \& Lis JT (2014) Genome-wide dynamics of Pol II elongation and its interplay 
with promoter proximal pausing, chromatin, and exons. elife 3: e02407

Jonkers I \& Lis JT (2015) Getting up to speed with transcription elongation by RNA polymerase II. Nat. Rev. Mol. Cell Biol. 16: 167-177

Joshi O, Wang S-Y, Kuznetsova T, Atlasi Y, Peng T, Fabre PJ, Habibi E, Shaik J, Saeed S, Handoko L, Richmond T, Spivakov M, Burgess D \& Stunnenberg HG (2015) Dynamic Reorganization of Extremely Long-Range Promoter-Promoter Interactions between Two States of Pluripotency. Cell Stem Cell 17: 748-757

Kolodziejczyk AA, Kim JK, Tsang JCH, Ilicic T, Henriksson J, Natarajan KN, Tuck AC, Gao X, Bühler M, Liu P, Marioni JC \& Teichmann SA (2015) Single Cell RNA-Sequencing of Pluripotent States Unlocks Modular Transcriptional Variation. Cell Stem Cell 17: 471-485

Ku M, Jaffe JD, Koche RP, Rheinbay E, Endoh M, Koseki H, Carr SA \& Bernstein BE (2012) H2A.Z landscapes and dual modifications in pluripotent and multipotent stem cells underlie complex genome regulatory functions. Genome Biol. 13: R85

Kumar B \& Elsässer SJ (2019) Quantitative Multiplexed ChIP Reveals Global Alterations that Shape Promoter Bivalency in Ground State Embryonic Stem Cells. Cell Rep. 28: 32743284.e5

Kumar V, Rayan NA, Muratani M, Lim S, Elanggovan B, Xin L, Lu T, Makhija H, Poschmann J, Lufkin T, Ng HH \& Prabhakar S (2016) Comprehensive benchmarking reveals H2BK2O acetylation as a distinctive signature of cell-state-specific enhancers and promoters. Genome Res. 26: 612-623

Kundu S, Ji F, Sunwoo H, Jain G, Lee JT, Sadreyev RI, Dekker J \& Kingston RE (2017) Polycomb Repressive Complex 1 Generates Discrete Compacted Domains that Change during Differentiation. Mol. Cell 65: 432-446.e5

Langer D, Martianov I, Alpern D, Rhinn M, Keime C, Dollé P, Mengus G \& Davidson I (2016) Essential role of the TFIID subunit TAF4 in murine embryogenesis and embryonic stem cell differentiation. Nat. Commun. 7: 11063

Larke MSC, Schwessinger R, Nojima T, Telenius J, Beagrie RA, Downes DJ, Oudelaar AM, Truch J, Graham B, Bender MA, Proudfoot NJ, Higgs DR \& Hughes JR (2021) Enhancers predominantly regulate gene expression during differentiation via transcription initiation. Mol. Cell 81: 983-997.e7

Liao Y, Smyth GK \& Shi W (2019) The R package Rsubread is easier, faster, cheaper and better for alignment and quantification of RNA sequencing reads. Nucleic Acids Res. 47: e47

Lin C, Garrett AS, De Kumar B, Smith ER, Gogol M, Seidel C, Krumlauf R \& Shilatifard A (2011) Dynamic transcriptional events in embryonic stem cells mediated by the super elongation 
complex (SEC). Genes Dev. 25: 1486-1498

Lloret-Llinares M, Karadoulama E, Chen Y, Wojenski LA, Villafano GJ, Bornholdt J, Andersson R, Core L, Sandelin A \& Jensen TH (2018) The RNA exosome contributes to gene expression regulation during stem cell differentiation. Nucleic Acids Res. 46: 11502-11513

Love MI, Huber W \& Anders S (2014) Moderated estimation of fold change and dispersion for RNA-seq data with DESeq2. Genome Biol. 15: 550

Marks H, Kalkan T, Menafra R, Denissov S, Jones K, Hofemeister H, Nichols J, Kranz A, Stewart AF, Smith A \& Stunnenberg HG (2012) The transcriptional and epigenomic foundations of ground state pluripotency. Cell 149: 590-604

Martire S, Gogate AA, Whitmill A, Tafessu A, Nguyen J, Teng Y-C, Tastemel M \& Banaszynski LA (2019) Phosphorylation of histone H3.3 at serine 31 promotes p300 activity and enhancer acetylation. Nat. Genet. 51: 941-946

McLaughlin K, Flyamer IM, Thomson JP, Mjoseng HK, Shukla R, Williamson I, Grimes GR, Illingworth RS, Adams IR, Pennings S, Meehan RR \& Bickmore WA (2019) DNA Methylation Directs Polycomb-Dependent 3D Genome Re-organization in Naive Pluripotency. Cell Rep. 29: 1974-1985.e6

Muhar M, Ebert A, Neumann T, Umkehrer C, Jude J, Wieshofer C, Rescheneder P, Lipp JJ, Herzog VA, Reichholf B, Cisneros DA, Hoffmann T, Schlapansky MF, Bhat $P$, von Haeseler A, Köcher T, Obenauf AC, Popow J, Ameres SL \& Zuber J (2018) SLAM-seq defines direct generegulatory functions of the BRD4-MYC axis. Science 360: 800-805

Muse GW, Gilchrist DA, Nechaev S, Shah R, Parker JS, Grissom SF, Zeitlinger J \& Adelman K (2007) RNA polymerase is poised for activation across the genome. Nat. Genet. 39: 15071511

Mylonas C, Lee C, Auld AL, Cisse II \& Boyer LA (2021) A dual role for H2A.Z.1 in modulating the dynamics of RNA polymerase II initiation and elongation. Nat. Struct. Mol. Biol.

Mylonas C \& Tessarz P (2018) Transcriptional repression by FACT is linked to regulation of chromatin accessibility at the promoter of ES cells. Life Sci. Alliance 1: e201800085

Nojima T, Gomes T, Grosso ARF, Kimura H, Dye MJ, Dhir S, Carmo-Fonseca M \& Proudfoot NJ (2015) Mammalian NET-Seq Reveals Genome-wide Nascent Transcription Coupled to RNA Processing. Cell 161: 526-540

Novo CL, Javierre B-M, Cairns J, Segonds-Pichon A, Wingett SW, Freire-Pritchett P, FurlanMagaril M, Schoenfelder S, Fraser P \& Rugg-Gunn PJ (2018) Long-Range Enhancer Interactions Are Prevalent in Mouse Embryonic Stem Cells and Are Reorganized upon Pluripotent State Transition. Cell Rep. 22: 2615-2627 
Ostapcuk V, Mohn F, Carl SH, Basters A, Hess D, lesmantavicius V, Lampersberger L, Flemr M, Pandey A, Thomä NH, Betschinger J \& Bühler M (2018) Activity-dependent neuroprotective protein recruits HP1 and CHD4 to control lineage-specifying genes. Nature 557: 739-743

Peng T, Zhai Y, Atlasi Y, Ter Huurne M, Marks H, Stunnenberg HG \& Megchelenbrink W (2020) STARR-seq identifies active, chromatin-masked, and dormant enhancers in pluripotent mouse embryonic stem cells. Genome Biol. 21: 243

Pintacuda G, Wei G, Roustan C, Kirmizitas BA, Solcan N, Cerase A, Castello A, Mohammed S, Moindrot B, Nesterova TB \& Brockdorff N (2017) hnRNPK Recruits PCGF3/5-PRC1 to the Xist RNA B-Repeat to Establish Polycomb-Mediated Chromosomal Silencing. Mol. Cell 68: 955-969.e10

Poleshko A, Shah PP, Gupta M, Babu A, Morley MP, Manderfield L, Ifkovits JL, Calderon D, Aghajanian H, Sierra-Pagán JE, Sun Z, Wang Q, Li L, Dubois NC, Morrisey EE, Lazar MA, Smith CL, Epstein JA \& Jain R (2017) Genome-Nuclear Lamina Interactions Regulate Cardiac Stem Cell Lineage Restriction. Cell 171: 573-587.e14

Rabani M, Levin JZ, Fan L, Adiconis X, Raychowdhury R, Garber M, Gnirke A, Nusbaum C, Hacohen N, Friedman N, Amit I \& Regev A (2011) Metabolic labeling of RNA uncovers principles of RNA production and degradation dynamics in mammalian cells. Nat.

Biotechnol. 29: 436-442

Sabari BR, Dall'Agnese A, Boija A, Klein IA, Coffey EL, Shrinivas K, Abraham BJ, Hannett NM, Zamudio AV, Manteiga JC, Li CH, Guo YE, Day DS, Schuijers J, Vasile E, Malik S, Hnisz D, Lee $\mathrm{TI}$, Cisse II, Roeder RG, et al (2018) Coactivator condensation at super-enhancers links phase separation and gene control. Science 361:

Sachs M, Onodera C, Blaschke K, Ebata KT, Song JS \& Ramalho-Santos M (2013) Bivalent chromatin marks developmental regulatory genes in the mouse embryonic germline in vivo. Cell Rep. 3: 1777-1784

Sanchez GJ, Richmond PA, Bunker EN, Karman SS, Azofeifa J, Garnett AT, Xu Q, Wheeler GE, Toomey CM, Zhang Q, Dowell RD \& Liu X (2018) Genome-wide dose-dependent inhibition of histone deacetylases studies reveal their roles in enhancer remodeling and suppression of oncogenic super-enhancers. Nucleic Acids Res. 46: 1756-1776

Schoenfelder S \& Fraser P (2019) Long-range enhancer-promoter contacts in gene expression control. Nat. Rev. Genet. 20: 437-455

Schofield JA, Duffy EE, Kiefer L, Sullivan MC \& Simon MD (2018) TimeLapse-seq: adding a temporal dimension to RNA sequencing through nucleoside recoding. Nat. Methods 15: 221-225

Schwalb B, Michel M, Zacher B, Frühauf K, Demel C, Tresch A, Gagneur J \& Cramer P (2016) TT- 
seq maps the human transient transcriptome. Science 352: 1225-1228

Schwanhäusser B, Busse D, Li N, Dittmar G, Schuchhardt J, Wolf J, Chen W \& Selbach M (2011) Global quantification of mammalian gene expression control. Nature 473: 337-342

Sheridan RM, Fong N, D’Alessandro A \& Bentley DL (2019) Widespread backtracking by RNA pol II is a major effector of gene activation, 5' pause release, termination, and transcription elongation rate. Mol. Cell 73: 107-118.e4

Siepel A, Bejerano G, Pedersen JS, Hinrichs AS, Hou M, Rosenbloom K, Clawson H, Spieth J, Hillier LW, Richards S, Weinstock GM, Wilson RK, Gibbs RA, Kent WJ, Miller W \& Haussler D (2005) Evolutionarily conserved elements in vertebrate, insect, worm, and yeast genomes. Genome Res. 15: 1034-1050

Søgaard TMM \& Svejstrup JQ (2007) Hyperphosphorylation of the C-terminal repeat domain of RNA polymerase II facilitates dissociation of its complex with mediator. J. Biol. Chem. 282: 14113-14120

Steurer B, Janssens RC, Geverts B, Geijer ME, Wienholz F, Theil AF, Chang J, Dealy S, Pothof J, van Cappellen WA, Houtsmuller AB \& Marteijn JA (2018) Live-cell analysis of endogenous GFP-RPB1 uncovers rapid turnover of initiating and promoter-paused RNA Polymerase II. Proc Natl Acad Sci USA 115: E4368-E4376

Surface LE, Fields PA, Subramanian V, Behmer R, Udeshi N, Peach SE, Carr SA, Jaffe JD \& Boyer LA (2016) H2A.Z.1 monoubiquitylation antagonizes BRD2 to maintain poised chromatin in escs. Cell Rep. 14: 1142-1155

Tuck AC, Natarajan KN, Rice GM, Borawski J, Mohn F, Rankova A, Flemr M, Wenger A, Nutiu R, Teichmann S \& Bühler M (2018) Distinctive features of lincRNA gene expression suggest widespread RNA-independent functions. Life Sci. Alliance 1: e201800124

Veloso A, Kirkconnell KS, Magnuson B, Biewen B, Paulsen MT, Wilson TE \& Ljungman M (2014) Rate of elongation by RNA polymerase II is associated with specific gene features and epigenetic modifications. Genome Res. 24: 896-905

Vierstra J, Rynes E, Sandstrom R, Zhang M, Canfield T, Hansen RS, Stehling-Sun S, Sabo PJ, Byron R, Humbert R, Thurman RE, Johnson AK, Vong S, Lee K, Bates D, Neri F, Diegel M, Giste E, Haugen E, Dunn D, et al (2014) Mouse regulatory DNA landscapes reveal global principles of cis-regulatory evolution. Science 346: 1007-1012

Wachutka L, Caizzi L, Gagneur J \& Cramer P (2019) Global donor and acceptor splicing site kinetics in human cells. elife 8:

Walter M, Teissandier A, Pérez-Palacios R \& Bourc'his D (2016) An epigenetic switch ensures transposon repression upon dynamic loss of DNA methylation in embryonic stem cells. 
elife 5:

Wang L, Zhou Y, Xu L, Xiao R, Lu X, Chen L, Chong J, Li H, He C, Fu X-D \& Wang D (2015) Molecular basis for 5-carboxycytosine recognition by RNA polymerase II elongation complex. Nature 523: 621-625

Weinberg DN, Papillon-Cavanagh S, Chen H, Yue Y, Chen X, Rajagopalan KN, Horth C, McGuire JT, Xu X, Nikbakht H, Lemiesz AE, Marchione DM, Marunde MR, Meiners MJ, Cheek MA, Keogh M-C, Bareke E, Djedid A, Harutyunyan AS, Jabado N, et al (2019) The histone mark H3K36me2 recruits DNMT3A and shapes the intergenic DNA methylation landscape. Nature 573: 281-286

Weintraub AS, Li CH, Zamudio AV, Sigova AA, Hannett NM, Day DS, Abraham BJ, Cohen MA, Nabet B, Buckley DL, Guo YE, Hnisz D, Jaenisch R, Bradner JE, Gray NS \& Young RA (2017) YY1 Is a Structural Regulator of Enhancer-Promoter Loops. Cell 171: 1573-1588.e28

West S, Gromak N \& Proudfoot NJ (2004) Human 5' --> 3' exonuclease Xrn2 promotes transcription termination at co-transcriptional cleavage sites. Nature 432: 522-525

Wu TP, Wang T, Seetin MG, Lai Y, Zhu S, Lin K, Liu Y, Byrum SD, Mackintosh SG, Zhong M, Tackett A, Wang G, Hon LS, Fang G, Swenberg JA \& Xiao AZ (2016) DNA methylation on $N(6)$-adenine in mammalian embryonic stem cells. Nature 532: 329-333

Yao M, Zhou X, Zhou J, Gong S, Hu G, Li J, Huang K, Lai P, Shi G, Hutchins AP, Sun H, Wang H \& Yao H (2018) PCGF5 is required for neural differentiation of embryonic stem cells. Nat. Commun. 9: 1463

Ying Q-L, Wray J, Nichols J, Batlle-Morera L, Doble B, Woodgett J, Cohen P \& Smith A (2008) The ground state of embryonic stem cell self-renewal. Nature 453: 519-523

Zhang T, Zhang Z, Dong Q, Xiong J \& Zhu B (2020) Histone H3K27 acetylation is dispensable for enhancer activity in mouse embryonic stem cells. Genome Biol. 21: 45

Zhao Y, Li H, Fang S, Kang Y, Wu W, Hao Y, Li Z, Bu D, Sun N, Zhang MQ \& Chen R (2016) NONCODE 2016: an informative and valuable data source of long non-coding RNAs. Nucleic Acids Res. 44: D203-8 
bioRxiv preprint doi: https://doi.org/10.1101/2021.06.11.448016; this version posted June 13, 2021. The copyright holder for this preprint (which was not certified by peer review) is the author/funder, who has granted bioRxiv a license to display the preprint in perpetuity. It is made available under aCC-BY-NC-ND 4.0 International license.

A

B
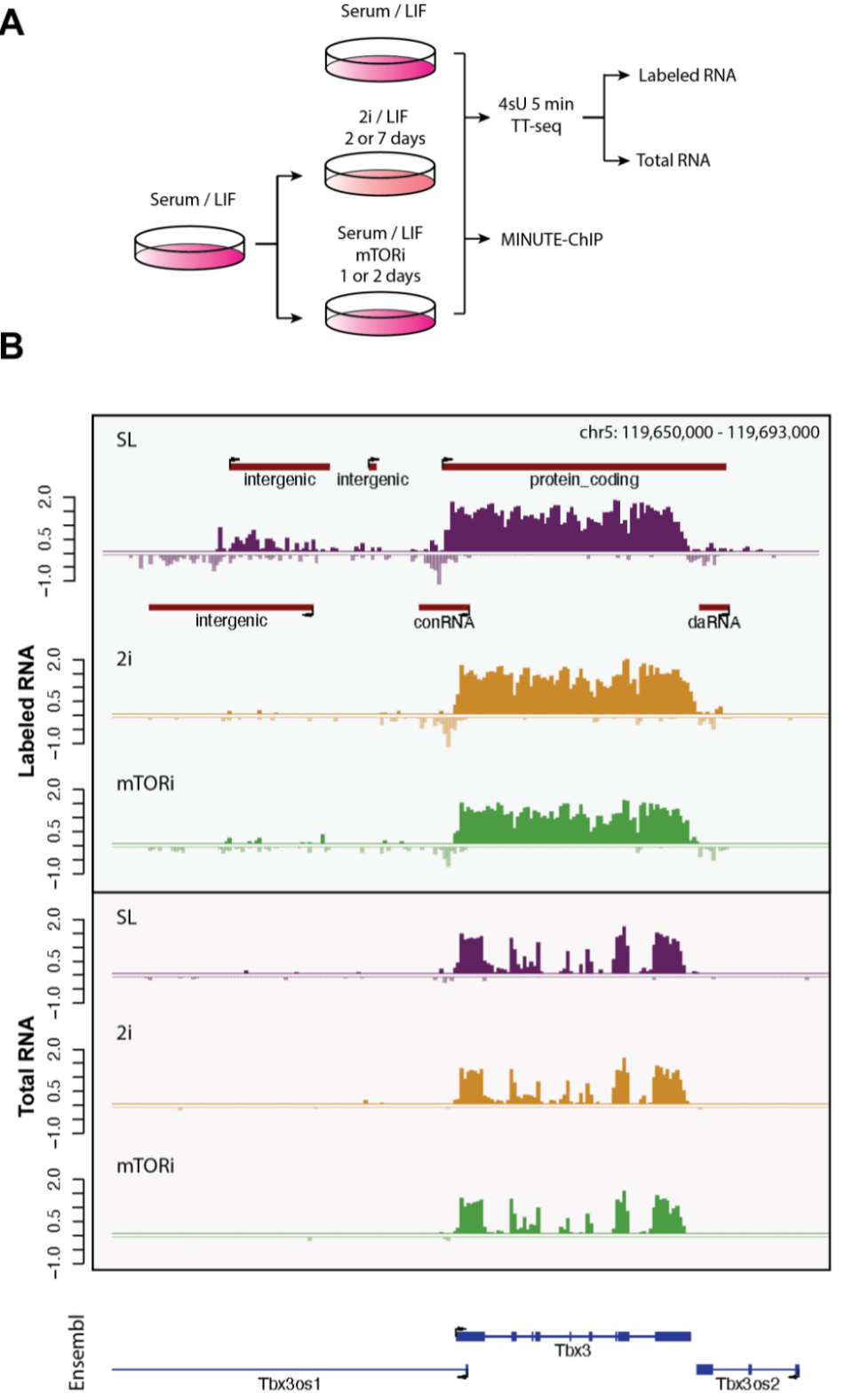

C

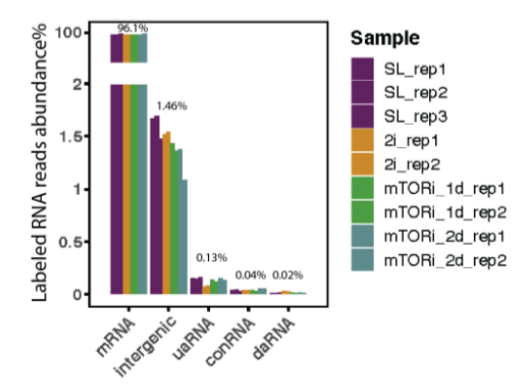

$\mathbf{E}$

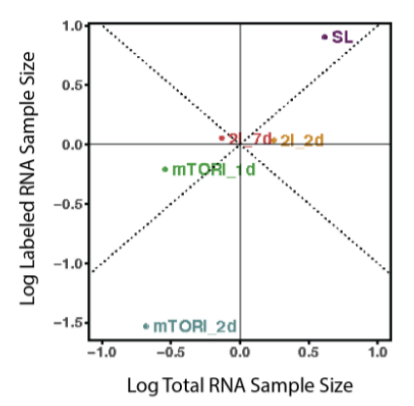

$\mathbf{F}$

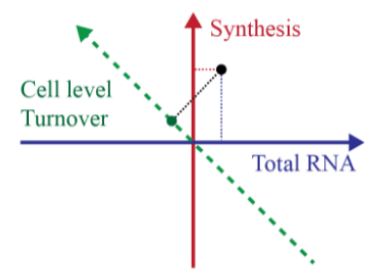

Turnover $=$ Synthesis - Total RNA (log scale)

G

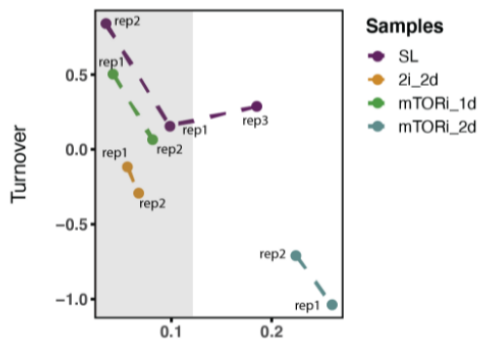

Cell density (million / cm2)

H

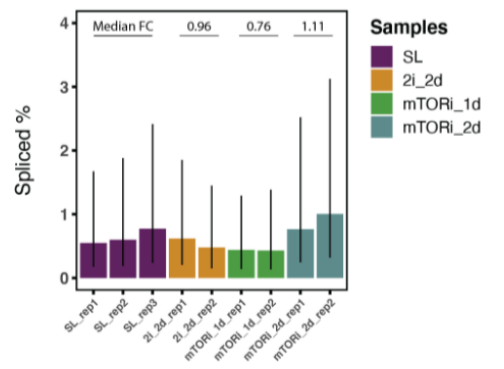

Figure 1. Mouse ES cells transcript annotation with TT-seq. 
A. Experimental Scheme for collecting TT-seq samples in Serum/LIF (SL), 2i/LIF (2i), Serum/LIF/mTORi (mTORi) conditions.

B. TT-seq nascent RNA and total RNA profiles of gene Tbx3, with annotated transcription units (TU, red) and Ensembl gene references (blue) in mm10.

C. Labeled RNA reads distribution by TU locations in percentage (y axis breaks from 2 to $40 \%$ ).

D. Labeled RNA TPM (transcript per million) by TU locations of each sample and replicate.

E. Labeled and total RNA sample sizes distribution of the mESC pluripotent states. Sample sizes are represented by the log-transformed DESeq's size factors after spike-in normalization.

F. A schematic diagram of cell level RNA turnover approximation by the contrast of labeled and total size factors, which equals the projection on the green diagonal dashed line.

G. Cell level turnover rates plotted against culture densities at time of harvesting. Replicates falling into the grey area of similar cell density were used to calculate spike-in normalized transcript abundance in Fig 2.

$H$. Proportions of spliced labeled RNA reads (CIGAR ' $N$ ') on Ensembl protein-coding genes. The error bar shows the $(0.25,0.75)$ quantile of spliced ratio. 
bioRxiv preprint doi: https://doi.org/10.1101/2021.06.11.448016; this version posted June 13, 2021. The copyright holder for this preprint (which was not certified by peer review) is the author/funder, who has granted bioRxiv a license to display the preprint in perpetuity. It is made available under aCC-BY-NC-ND 4.0 International license.

A
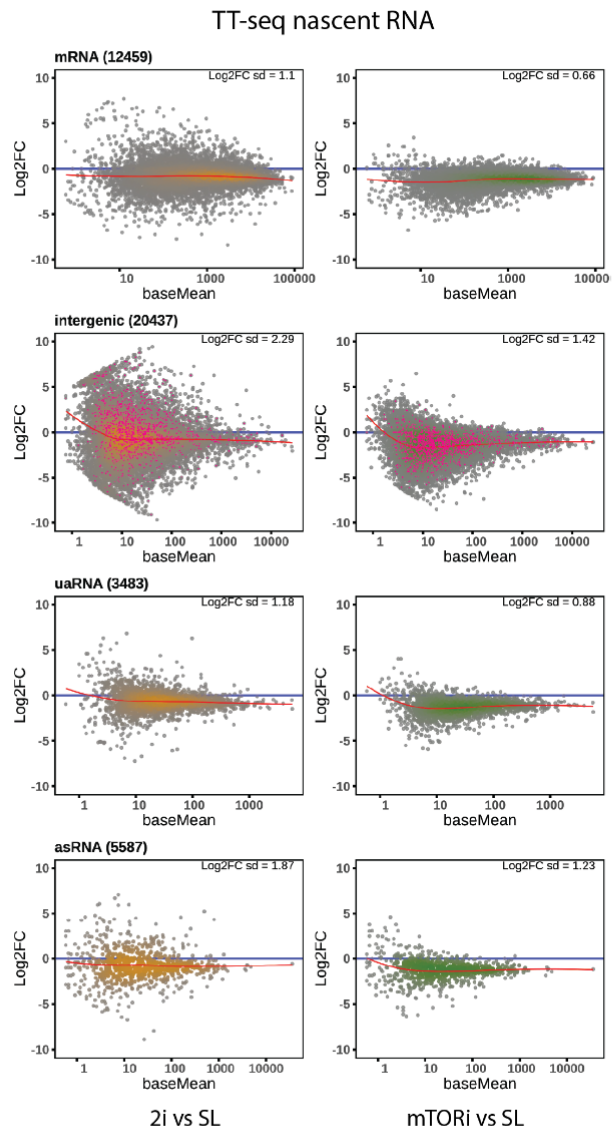

B

Type $\cdot$ mRNA $\bullet$ intergenic $\cdot$ uaRNA $\cdot$ asRNA

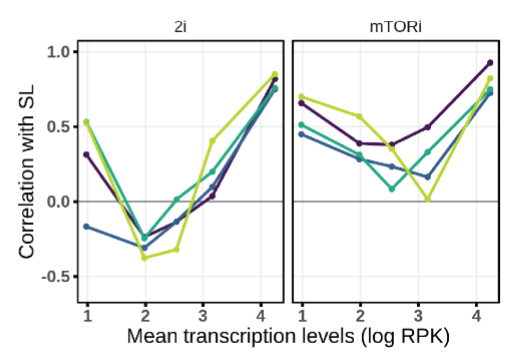

C

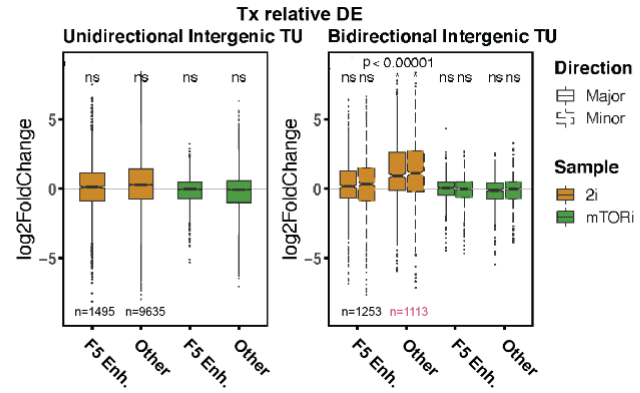

D

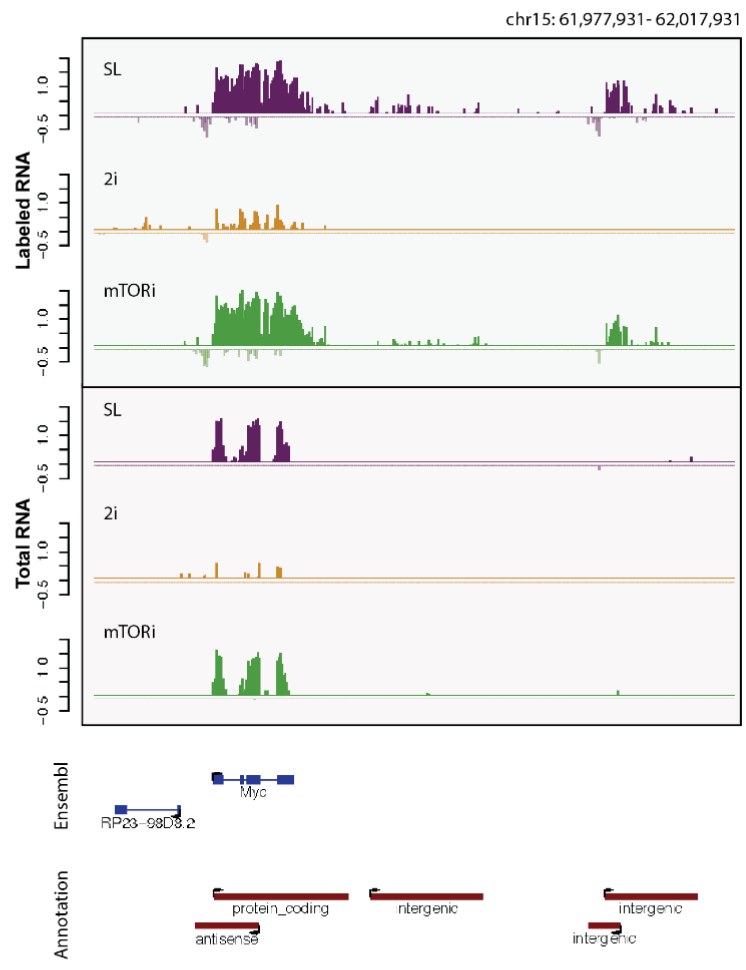

E

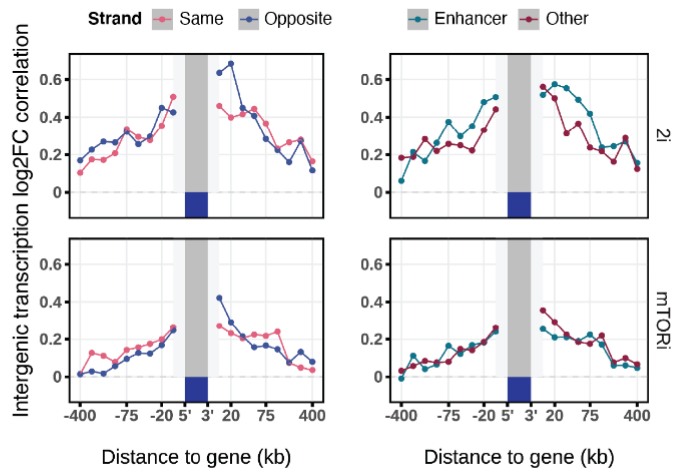




\section{Figure 2. Pluripotent states transcription rewiring.}

A. Spike-in normalized MA-plots in the contrasts of $2 i$ ( 2 days, yellow) and mTORi ( 1 day, green)

to SL state. Local regression lines are in red. Bidirectional non-enhancer intergenic TUs in C are highlighted in pink.

B. Pearson's correlation of log labeled RNA RPK by mean transcription level bins in the same contrasts.

C. DESeq2 internal normalized differential expression tests of intergenic RNA labeled RNA read counts. Major and minor TU directions were assigned by labeled RNA RPKs. FANTOM5 (Andersson et al, 2014) mouse enhancers were overlapped with the intergenic TUs. Statistical test was performed with two-tailed Student's t-test of log2 fold changes.

D. Spike-ins normalized labeled and total RNA profiles of Myc gene neighborhood

E. Log2FC correlation of neighboring intergenic TUs and genes by genomic distance bins, separately for the relative strandedness to genes and the combined enhancer annotations (FANTOM5(Andersson et al, 2014), ChromHMM(Pintacuda et al, 2017) and STARR-seq(Peng et al, 2020) ). 
A

Sample $-\mathrm{SL}-2 \mathrm{i}-\mathrm{mTORi}$

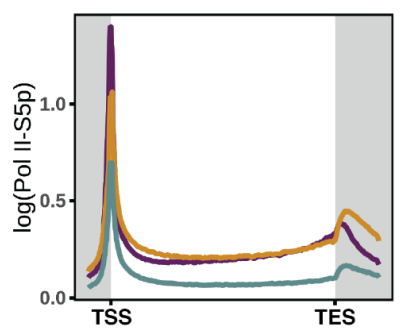

B

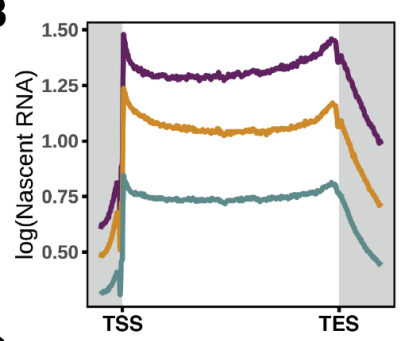

C

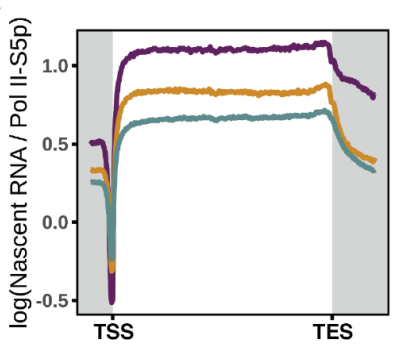

D

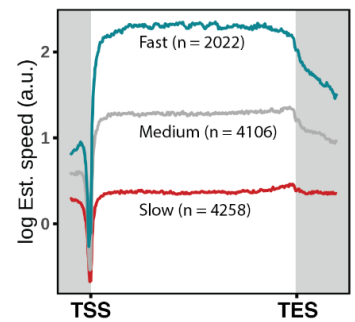

E

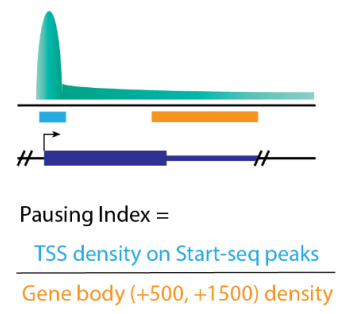

$\mathbf{F}$

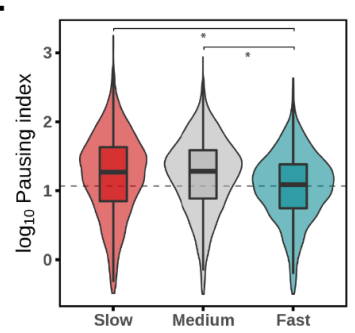

G

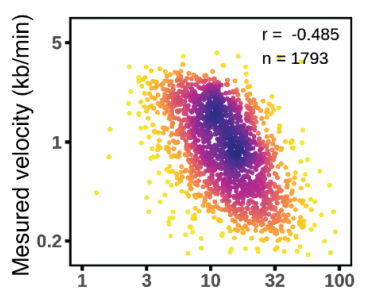

I Pol II S5p density (RPK)

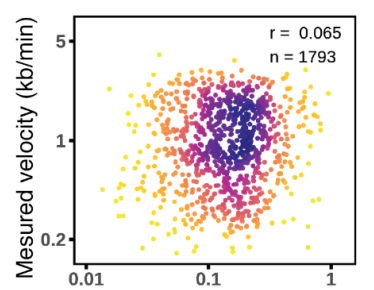

RNA synthesis (copy/min)

K

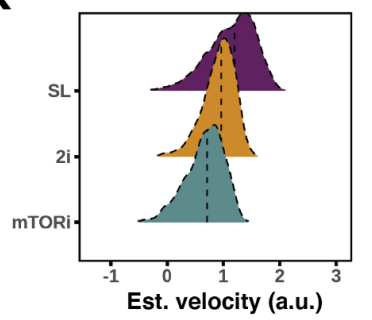

H

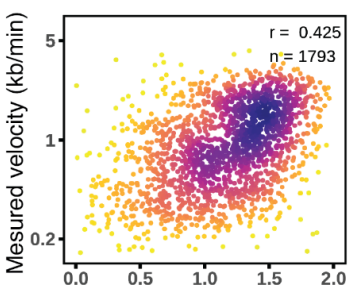

Est. velocity (a.u.)

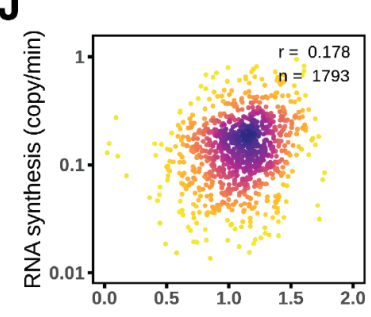

Est. RNA synthesis (a.u.)

$\mathbf{L}$

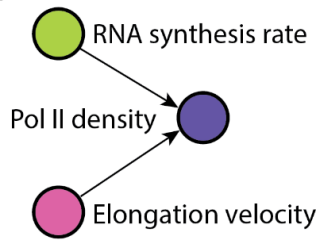

Figure 3. Elongation velocity estimation in the pluripotent states.

A-C. Quantitative MINUTE-ChIP mean coverage profiles of Pol II S5p, spike-ins normalized TT-seq nascent RNA and their ratio as the estimated elongation velocity.

D. K-means grouped average profiles of estimated velocity in the SL condition, the same condition for F-J.

E. Illustration of pausing index calculation (Materials and Methods).

F. Pausing indexes of Pol II S5p by different elongation velocity groups in the SL condition (* Student's t-test $p<2.2 e-16)$. 
G. Correlation of measured elongation velocity (Jonkers et al, 2014)(Materials and Methods) and

Pol II S5p gene body occupancy.

H. Correlation of GRO-seq measured velocity and estimated velocity by TT-seq nascent RNA and

Pol II S5p ChIP ratio.

I. Correlation of measured velocity (Jonkers et al, 2014) and TT-seq measured RNA synthesis rates.

J. Correlation of TT-seq measured RNA synthesis rates and estimated RNA synthesis rate by Pol II S5p density and GRO-seq measured velocity (Jonkers et al, 2014).

K. Ridge distribution of estimated elongation velocity of the pluripotent states.

L. A scheme describing the relationship of RNA synthesis rate, elongation velocity and Pol II gene occupancy. 
A
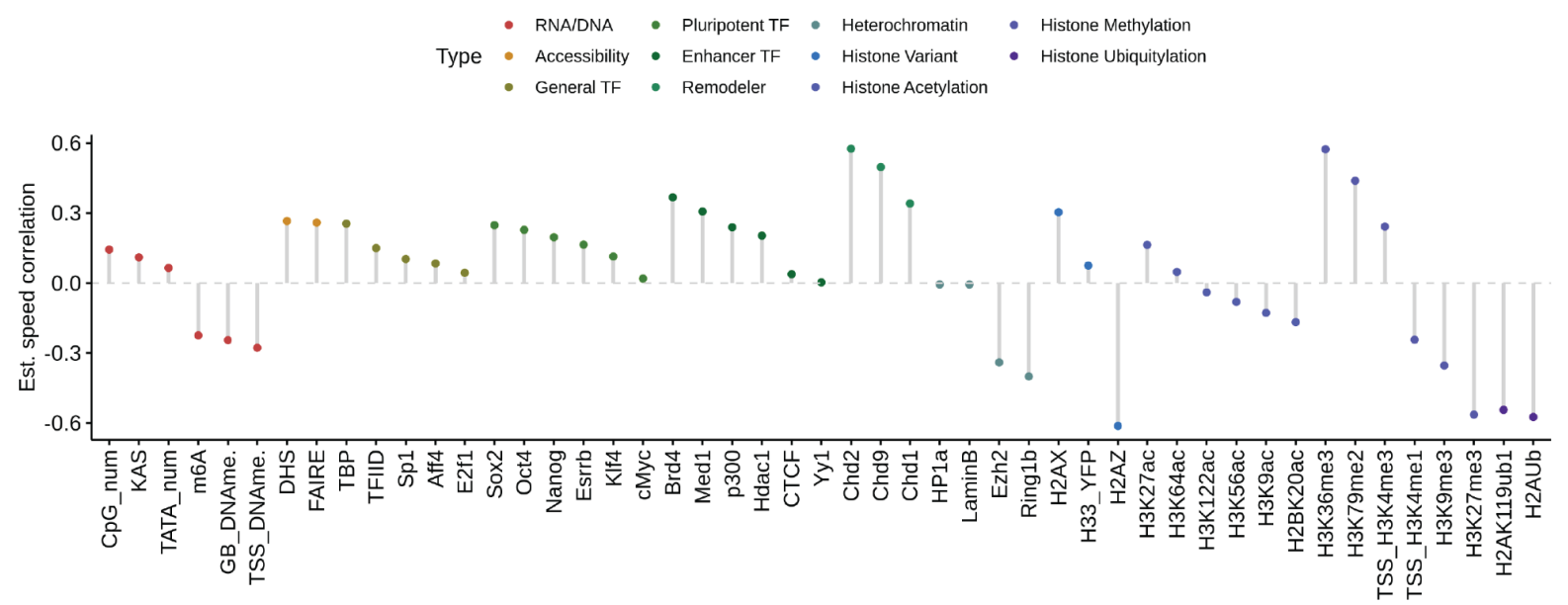

B

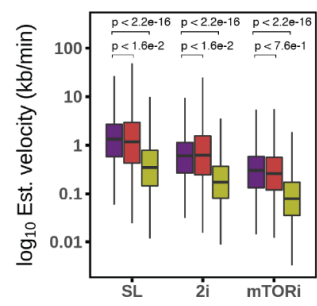

C
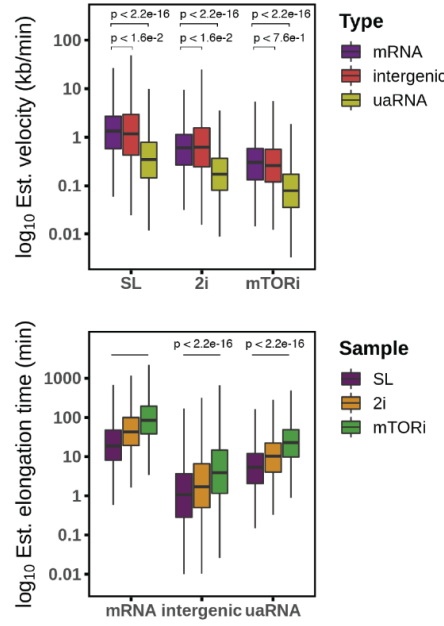

审 UaRNA
D

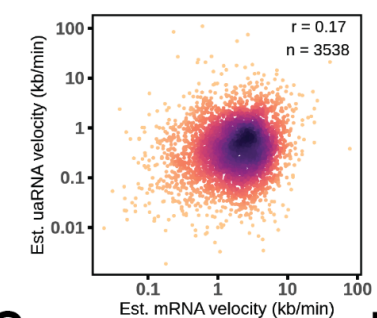

G

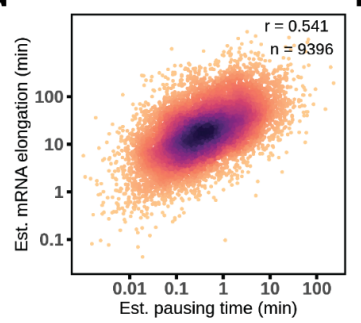

$\mathbf{E}$

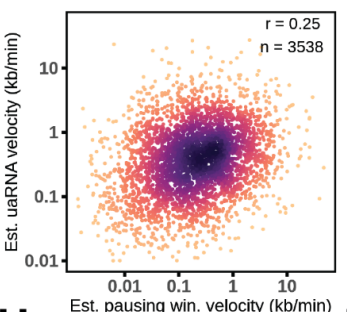

H

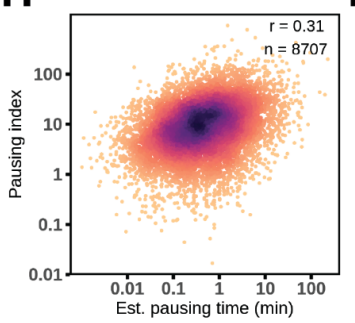

$\mathbf{F}$
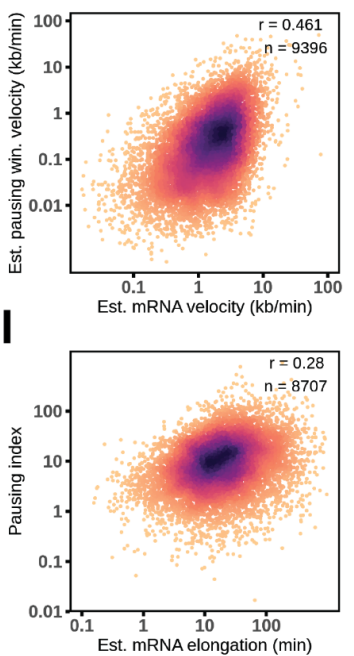

Figure 4. Transcription elongation velocity interpretation.

A. Correlation of estimated gene elongation velocity $(n=10611)$ with sequence and chromatin features (Materials and Methods).

B. Estimated velocity scaled by GRO-seq measured velocity plotted across the culture conditions and TU types. p-values were tested with Student's t-test in log scale. 
C. Estimated velocity scaled by GRO-seq measured velocity plotted across the culture conditions and TU types and estimated elongation time from the respective TU lengths. P-values were tested with Student's t-test in log scale.

D-F. Estimated velocity correlation between mRNA, paired uaRNA and mRNA TSS pausing window by Start-seq. Estimated elongation dynamic parameters were in SL condition, the same as below.

G-H. Correlation of estimated pausing duration on Start-seq TSS intervals with gene body elongation time and pausing index.

I. Correlation between estimated mRNA gene body elongation time and pausing index. 
bioRxiv preprint doi: https://doi.org/10.1101/2021.06.11.448016; this version posted June 13, 2021. The copyright holder for this preprint (which was not certified by peer review) is the author/funder, who has granted bioRxiv a license to display the preprint in perpetuity. It is made available under aCC-BY-NC-ND 4.0 International license.

A

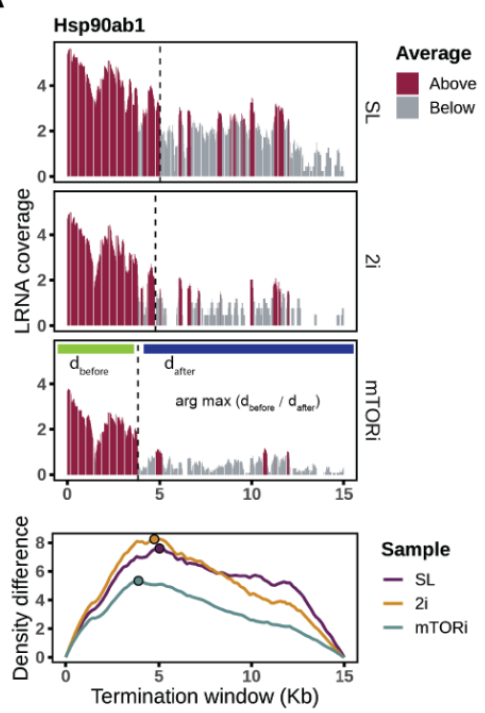

D
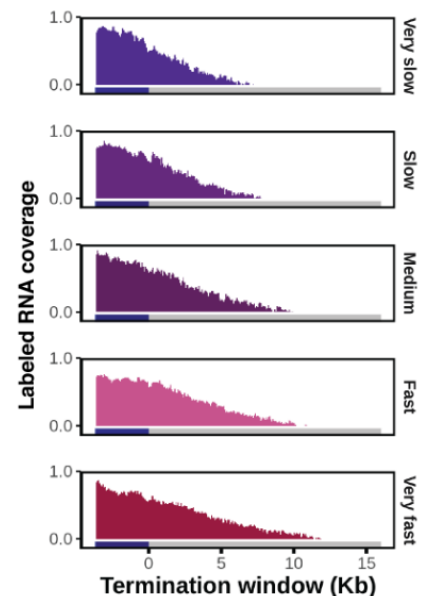

G
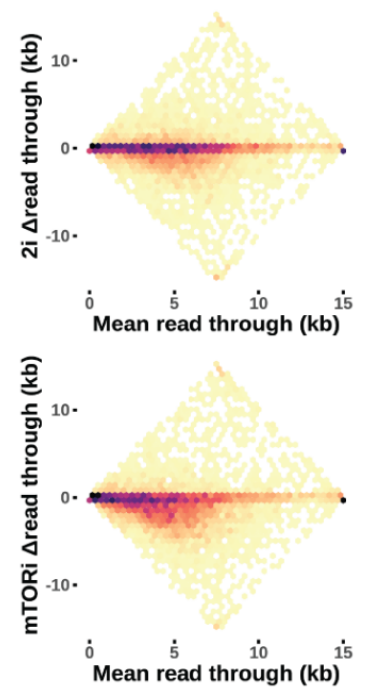

B

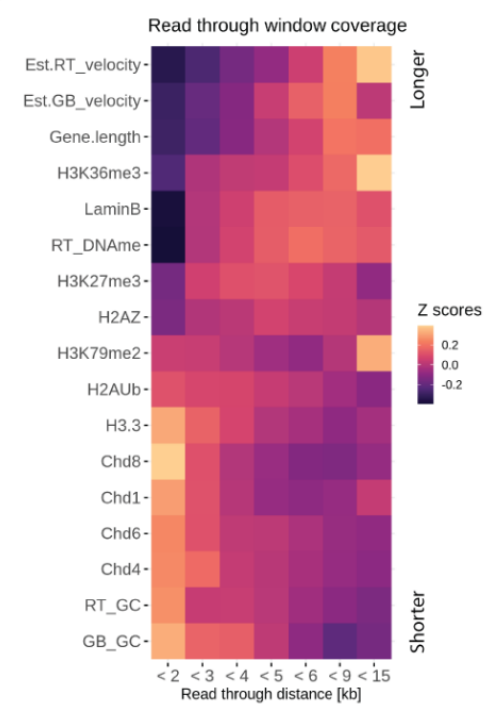

$\mathbf{E}$

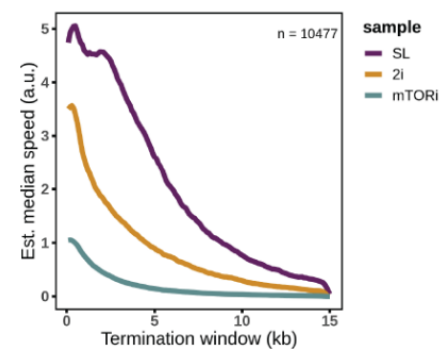

I
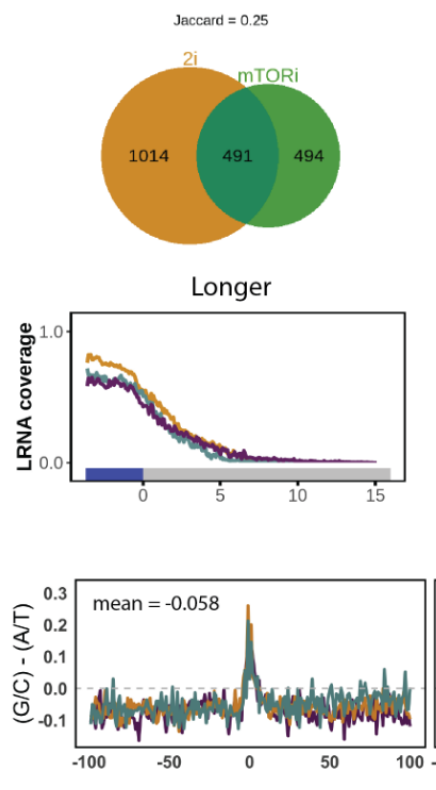

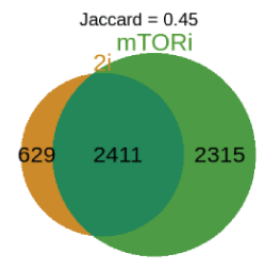

Shorter

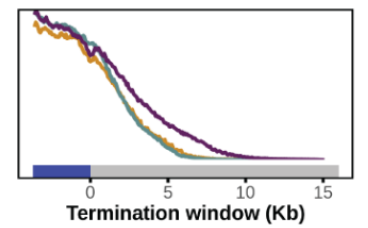

C

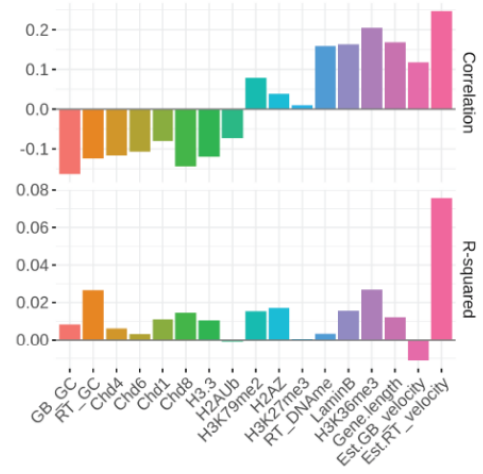

F

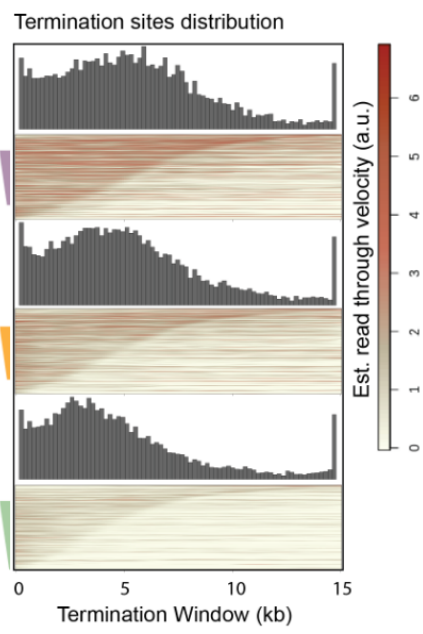

J

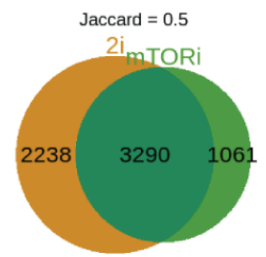

Unchanged
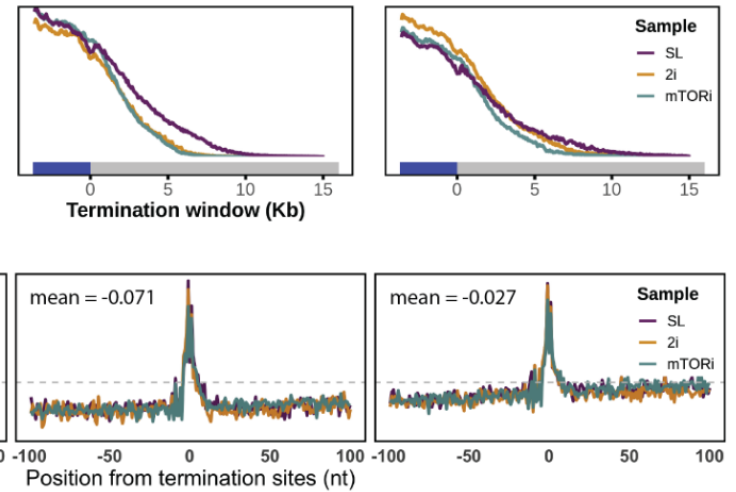


\section{Figure 5. Transcription termination read-through with elongation velocity.}

A. Illustration of termination site detection algorithm on gene Hsp90ab1, by maximizing the read density contrast as shown in the sliding curves (bottom) (Materials and Methods). The ultimate termination sites were indicated by dash lines and solid points for the three cell states.

B. Gene features and chromatin features termination window occupancy by binned read-through distances. Values were log normal transformed and standardized to z-scores.

C. Correlation of read-through distances with individual chromatin features (upper); multivariate linear regression decomposed R-squared values for the read-through distance explanation (lower) (Materials and Methods).

D. Labeled RNA median coverage in the termination window ordered by measured elongation velocity (Jonkers et al, 2014).

E. Estimated elongation velocity median coverage in the termination window by the mESC states.

F. Termination sites distribution (above) and estimated elongation velocity coverage heatmaps (below) by the order of read through distance in each condition.

G. Scatter plots of read-though distance changes in $2 \mathrm{i}$ and mTORi states with mean read-through distance.

$\mathrm{H}-\mathrm{J}$. Classes of read through distance changes in $2 \mathrm{i}$ and mTORi state. Top, Venn diagrams with Jaccard overlapping index; middle, labeled RNA reads coverage from the last exon (blue box) to $15 \mathrm{~kb}$ downstream termination window (grey box); bottom, GC versus AT nucleotide mean frequency contrast in the $100 \mathrm{bp}$ flanking region around termination sites. 
bioRxiv preprint doi: https://doi.org/10.1101/2021.06.11.448016; this version posted June 13, 2021. The copyright holder for this preprint (which was not certified by peer review) is the author/funder, who has granted bioRxiv a license to display the preprint in perpetuity. It is made available under aCC-BY-NC-ND 4.0 International license.

A
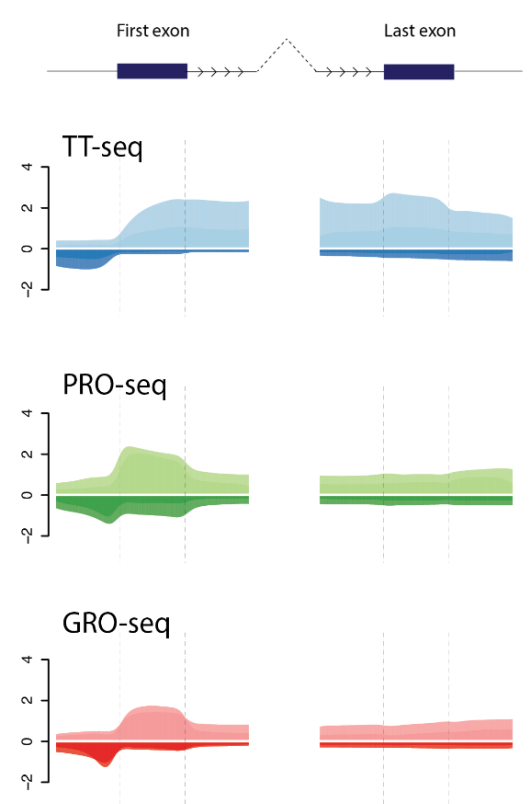

G

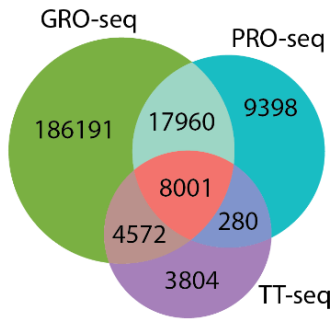

Intergenic TUs

I
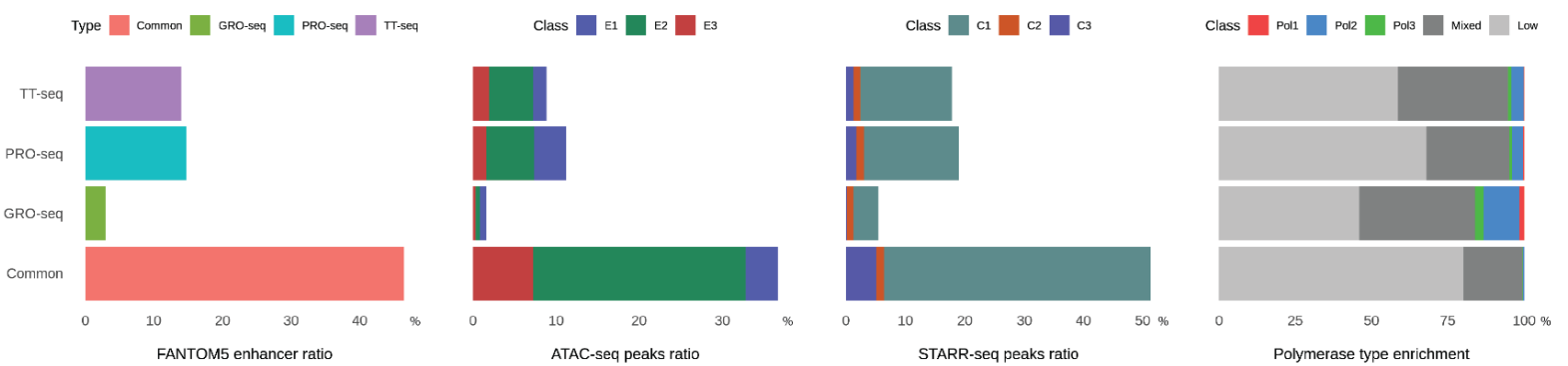

D

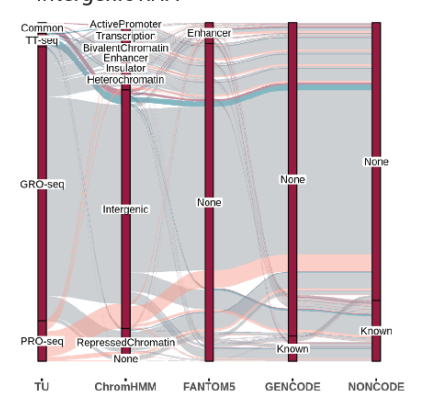

E

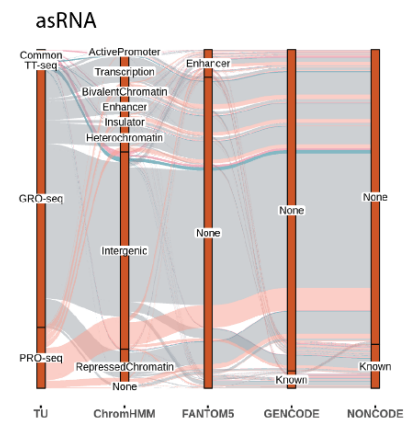

H
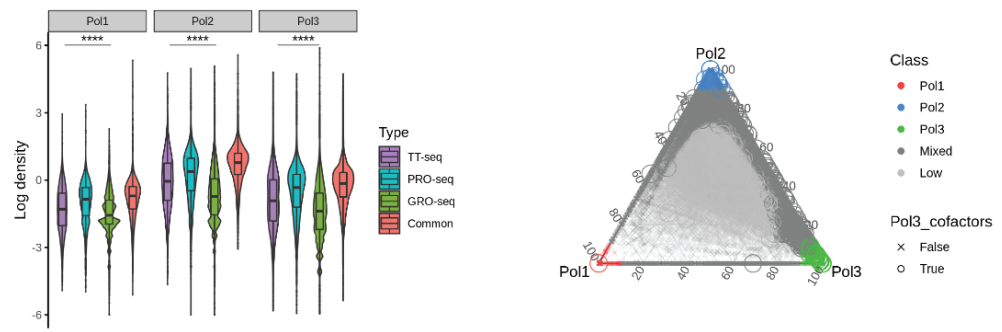

Total intergenic TUs

Polymerase type enrichment

Figure EV1. Nascent RNA-seq method comparison. 
A. Read coverages on the first and the last exons with $2 \mathrm{~kb}$ flanking regions and the adjacent introns (arrows). Exon and intron coverages were resized to the same dimension and plotted by log mean.

B. The ratios of intron versus exon nascent RNA reads density on Ensembl protein-coding genes across different nascent RNA sequencing methods.

C. TU annotation relative total length recovery test by TT-seq bam file random subsetting under $(0.1,0.2,0.4,0.6,0.8,1)$ for different TU types.

D-E. Comparison of intergenic and cis-antisense RNAs from different nascent RNA-seq methods matching with public references (GENCODE(Frankish et al, 2021), FANTOM5 enchancer(Andersson et al, 2014), NONCODE(Zhao et al, 2016)).

F. Venn diagram of GRO-seq, PRO-seq and TT-seq intergenic RNAs.

G. RNA Pol I, II and III occupancy (Jiang et al, 2020) on the total intergenic TUs. Student's t-test was performed with the common TUs against the method-specific TUs (****p $<2 \mathrm{e}-16)$.

H. A ternary plot of Pol I, II and III enrichment on the GRO-seq, PRO-seq and TT-seq combined intergenic TU annotations. Pol III co-factors binding sites (Carrière et al, 2012) were pinpointed for Pol III class assignment cross-validation.

I. Common overlapped and method specific intergenic RNAs proportions with FANTOM5 enhancers (Andersson et al, 2014), ATAC-seq peaks (Atlasi et al, 2019), STARR-seq peaks (Peng et al, 2020) and Pol I-III occupancy in $\mathrm{H}$. 
bioRxiv preprint doi: https://doi.org/10.1101/2021.06.11.448016; this version posted June 13, 2021. The copyright holder for this preprint (which was not certified by peer review) is the author/funder, who has granted bioRxiv a license to display the preprint in perpetuity. It is made available under aCC-BY-NC-ND 4.0 International license.

A

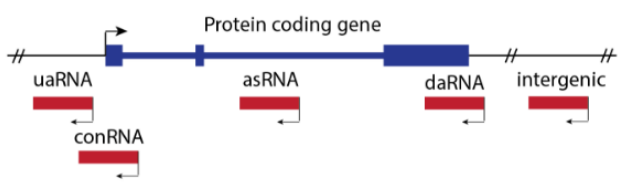

C
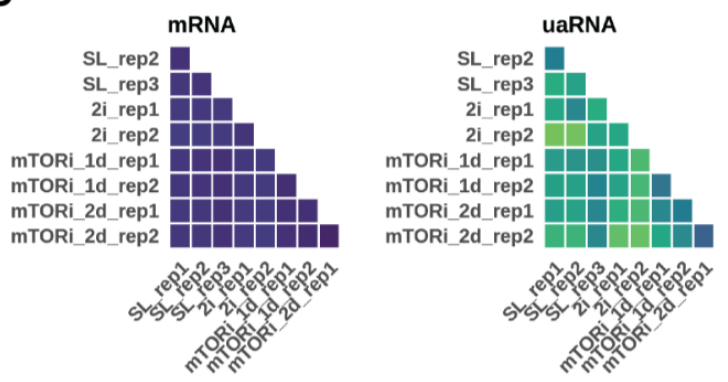

B

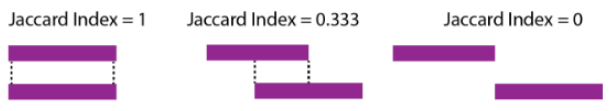

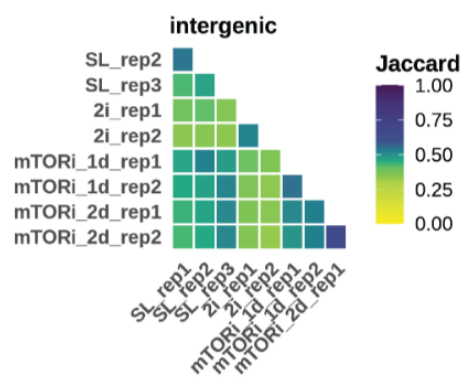

D

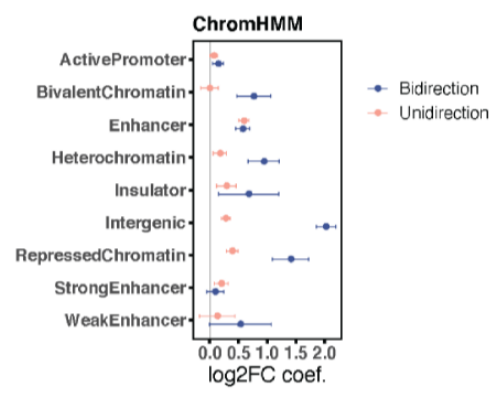

F

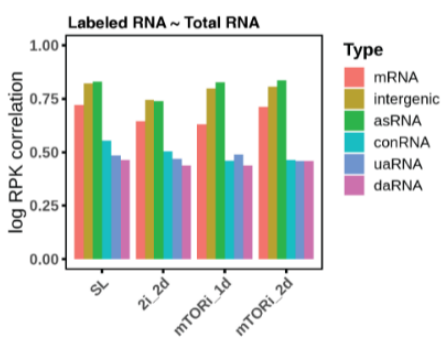

H

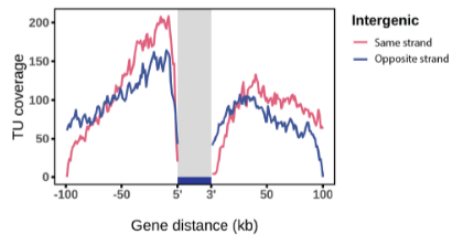

I

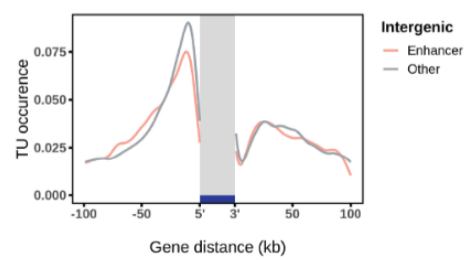

E

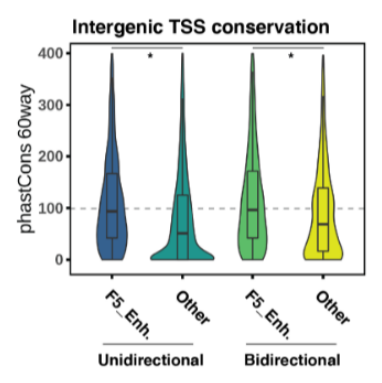

G

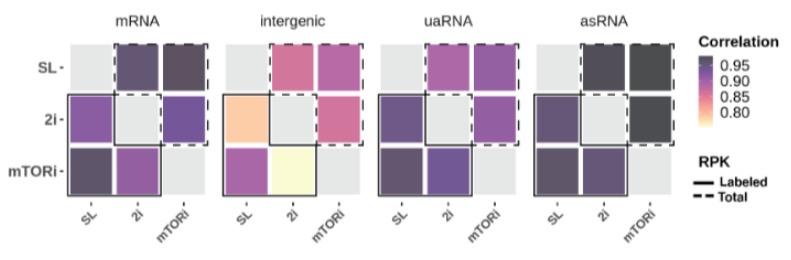

J
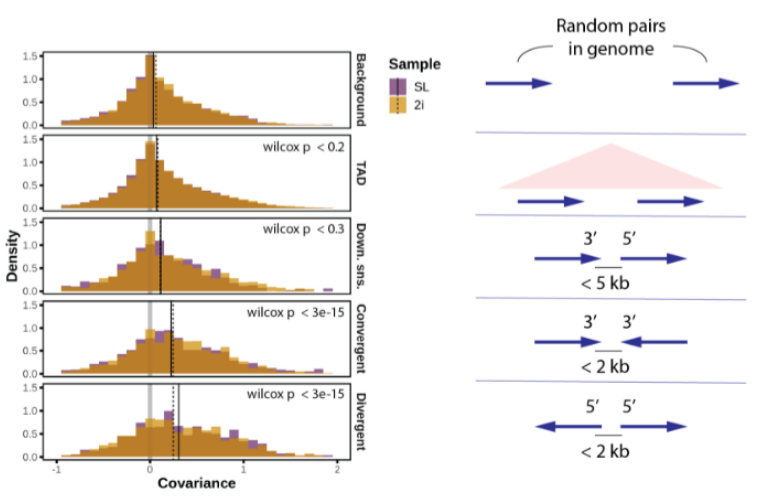


\section{Figure EV 2. TU annotation and transcription variation.}

A. Gene associated ncRNA types were named by their TSS locations relative to the gene TSS: upstream antisense RNA $(-1 \mathrm{~kb}, 0)$, convergent RNA $(0,+1 \mathrm{~kb})$, cis-antisense RNA (within gene body), downstream antisense RNA (TTS, TTS $+1 \mathrm{~kb}$ ) and intergenic RNA.

B. Illustration of Jaccard index of annotated TUs comparison.

C. Jaccard indexes of mRNA, uaRNA, asRNA and intergenic RNA intervals similarity in pairwise comparison between each sample and replicate.

D. The coefficients of ChromHMM states are in response to the internal normalised intergenic RNA $\log 2 \mathrm{FC}$ differential transcription in $2 \mathrm{i} 2$ days transition. Two separate logistic regression models were trained for the unidirectional and bidirectional intergenic TUs. Each states' coefficients were plotted with the respective logistic regression confidence intervals.

E. Intergenic TU promoter (-500 bp, 200 bp) evolution conservation scores from phastCons 60way (Siepel et al, 2005) with the same groups in Fig $2 \mathrm{C}$ (*Student's t-test $\mathrm{p}<2.2 \mathrm{e}-16$ ).

F. Pearson's correlation between labeled RNA and total RNA by each TU location and pluripotent state with merged replicates and log RPK on the combined TUs, the same for G.

G. Pearson's correlation between the pluripotent states by labeled and total RNA log RPK.

$\mathrm{H}$. Intergenic TU intervals stack coverage in the gene $\pm 100 \mathrm{~kb}$ neighborhood by relative strandedness.

I. Intergenic TU TSS occurrence by enhancer $(n=3950)$ and other $(n=4081)$ states in genes \pm 100 kb neighborhood $(n=11684)$. 
bioRxiv preprint doi: https://doi org/10.1101/2021.06.11.448016; this version posted June 13, 2021. The copyright holder for this preprint (which was not certified by peer review) is the author/funder, who has granted bioRxiv a license to display the preprint in perpetuity. It is made available under aCC-BY-NC-ND 4.0 International license.

J. Single-cell gene expression (Buettner et al, 2015) covariance distribution by the gene pairs of random background, within topological associated domain (TAD), consecutive downstream sense, $3^{\prime}$ ends convergence and promoter divergence. Wilcoxon test was performed against the background covariance. Median covariances of each gene positioning type were indicated for both SL and 2i states. 
A
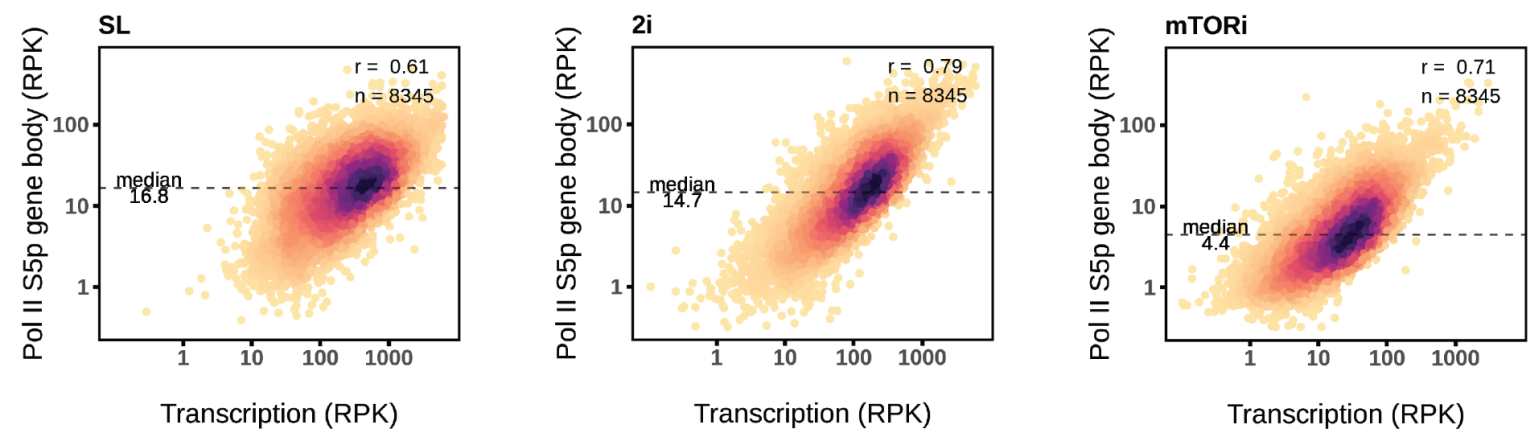

B
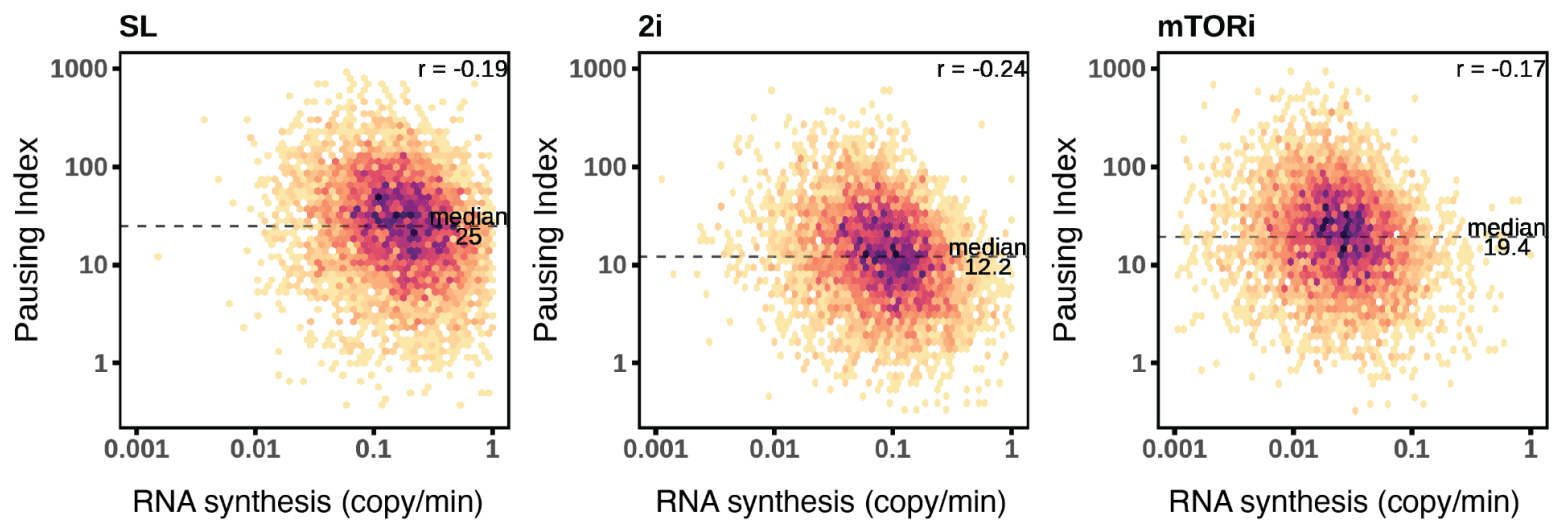

C
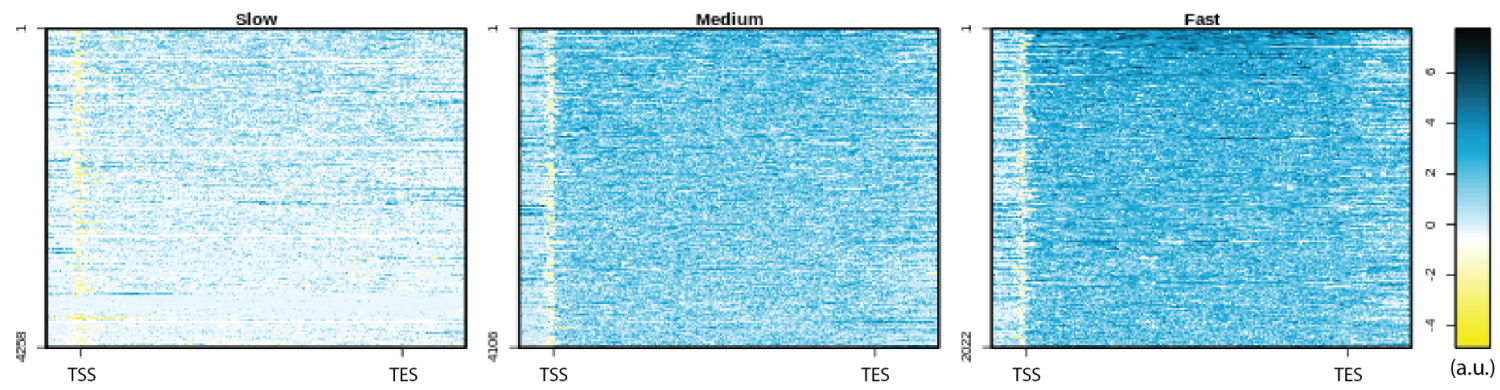

Figure EV 3. Pluripotent states transcription profiles.

A. Scatter plots of Pol II S5p gene body occupancy and TT-seq nascent RNA reads density.

Pearson's correlation was performed on the log scale, the same as in B.

B. Pausing indexes by Pol II S5p compared to RNA synthesis rates for each pluripotent condition.

The medians of pausing indexes and Pearson's correlation coefficients were indicated. 
bioRxiv preprint doi: https://doi.org/10.1101/2021.06.11.448016; this version posted June 13, 2021. The copyright holder for this preprint (which was not certified by peer review) is the author/funder, who has granted bioRxiv a license to display the preprint in perpetuity. It is made available under aCC-BY-NC-ND 4.0 International license.

C. K-means grouped estimated elongation velocity gene coverages were plotted in log scale.

Upstream $2 \mathrm{~kb}$ and downstream $4 \mathrm{~kb}$ were extended from Ensembl protein-coding gene intervals. 
A
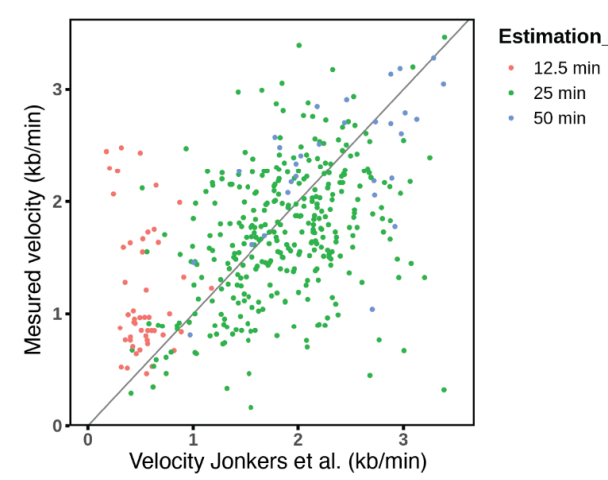

- $25 \mathrm{~min}$

- $50 \mathrm{~min}$

C

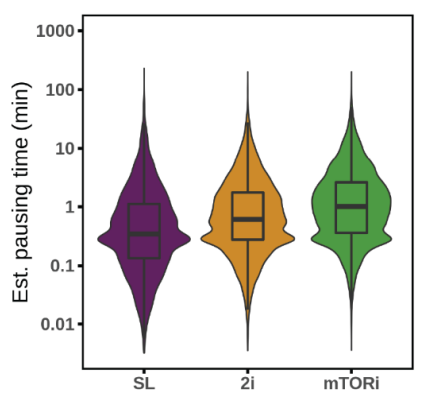

B
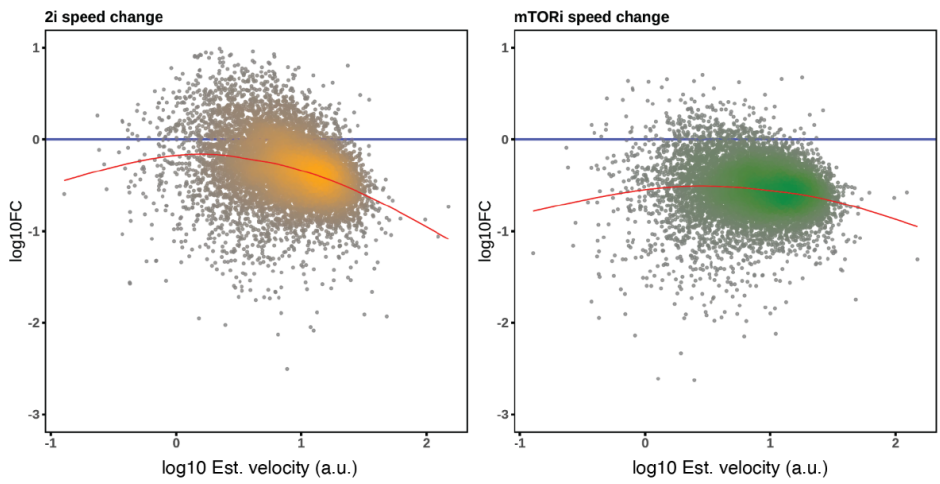

Figure EV4. Pausing index and elongation velocity comparison.

A. Comparison of the provided elongation velocity at the specified time points (Jonkers et al, 2014) and recalculated multi-time-point velocity estimates by linear regression (Materials and Methods).

B. MA-plots of elongation velocity changes in $2 \mathrm{i}$ and mTORi conditions against estimated velocity in SL condition. Local regression lines were appended to illustrate the trend of changes.

C. Estimation of pausing time in STAR-seq TSS intervals by the pluripotent states. Transcription velocity were scaled according to the external GRO-seq measured velocity. 
bioRxiv preprint doi: https://doi.org/10.1101/2021.06.11.448016; this version posted June 13, 2021. The copyright holder for this preprint (which was not certified by peer review) is the author/funder, who has granted bioRxiv a license to display the preprint in perpetuity. It is made available under aCC-BY-NC-ND 4.0 International license.

A
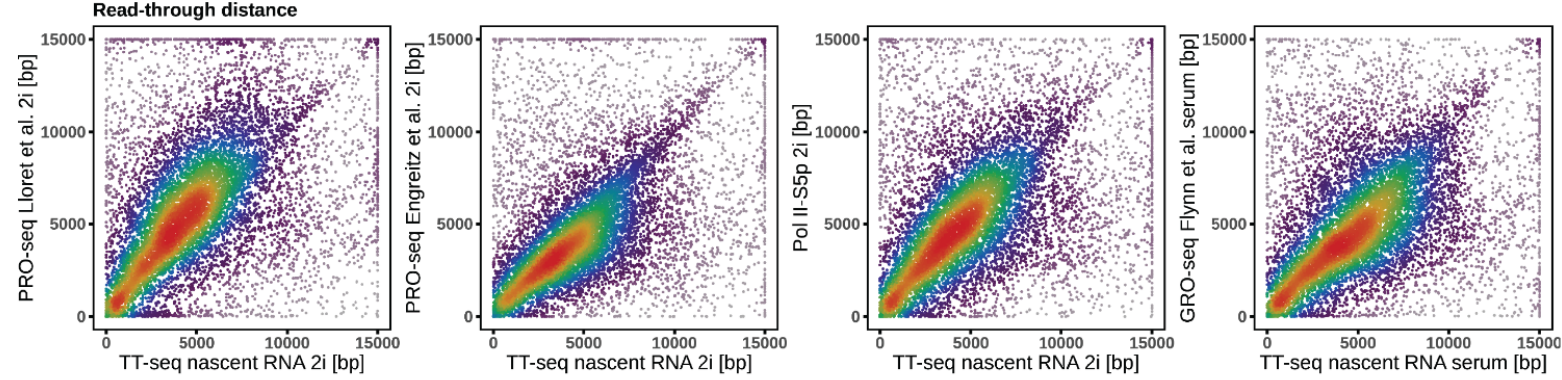

B
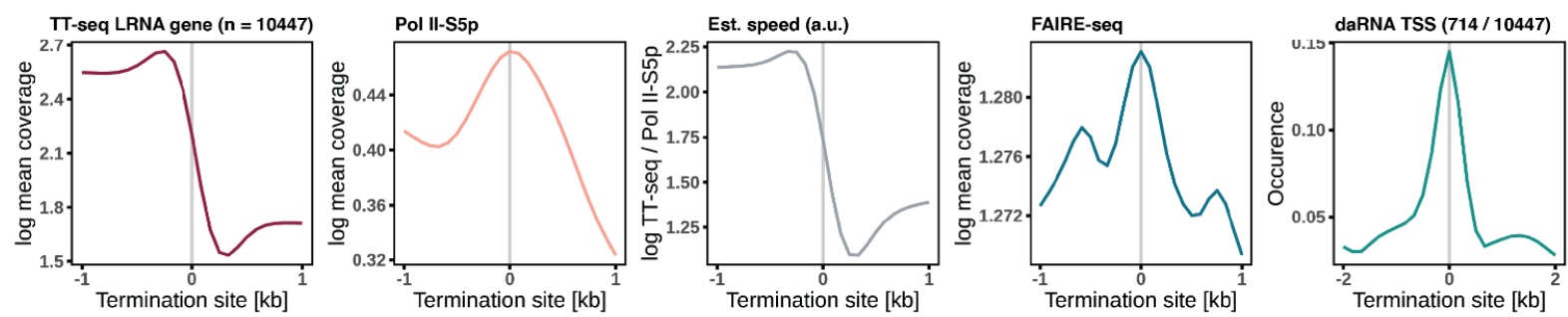

\section{C}

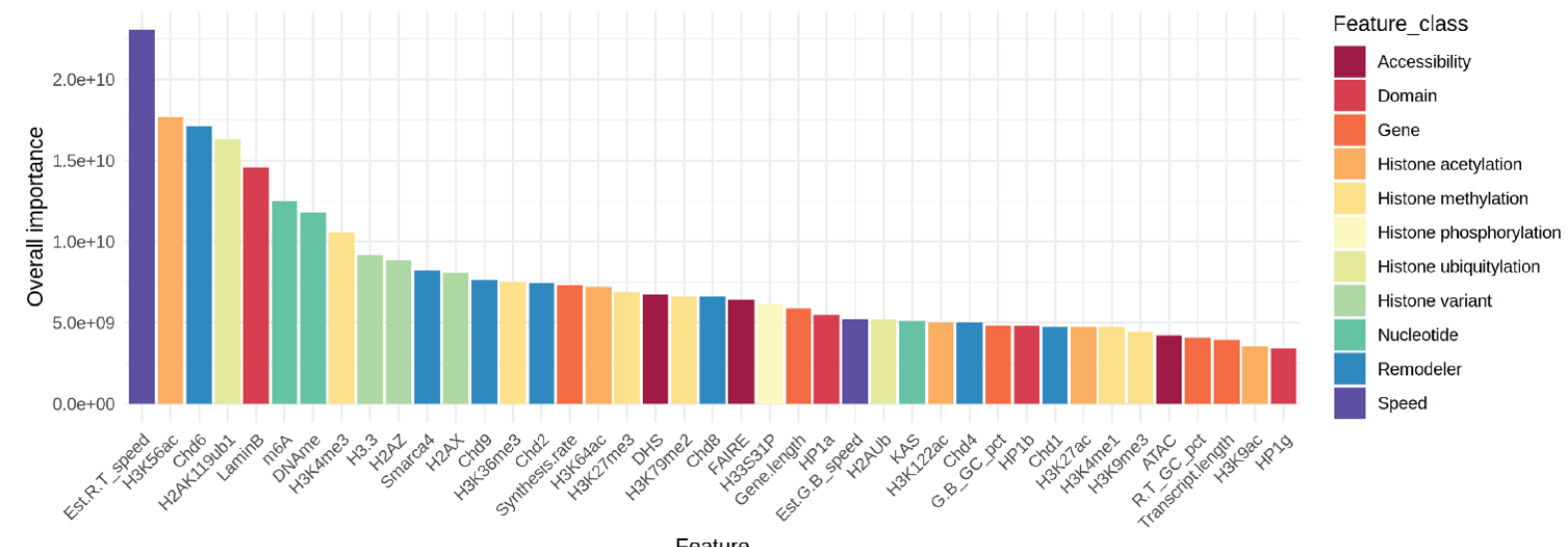

D

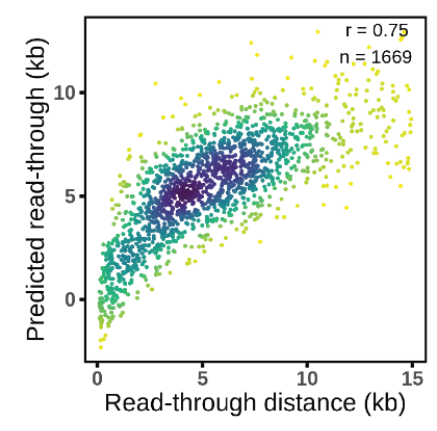

$\mathbf{E}$

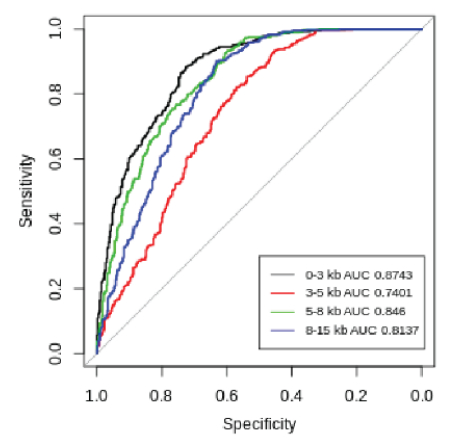


Figure EV5. Transcription termination sites comparison and explanation.

A. Read-through distances called by TT-seq, PRO-seq and Pol II S5p coverages in the termination window were compared by scatter plots.

B. Average coverage around $\pm 1 \mathrm{~kb}$ termination sites of TT-seq nascent RNA, Pol II S5p, estimated elongation velocity, FAIRE-seq and daRNA TSS occurrence with 10447 protein-coding genes.

C. Gradient boosting machine (gbm) model's feature importance of predicting read-through distance. 41 genomic features were used, the same as below.

D. Comparison of the actual read-through distances and the predicted distances on the hold-out test set by the gbm model.

E. A receiver operating characteristic curve $(\mathrm{ROC})$ of showing read-through distance groups prediction performance with features as described above. 
A

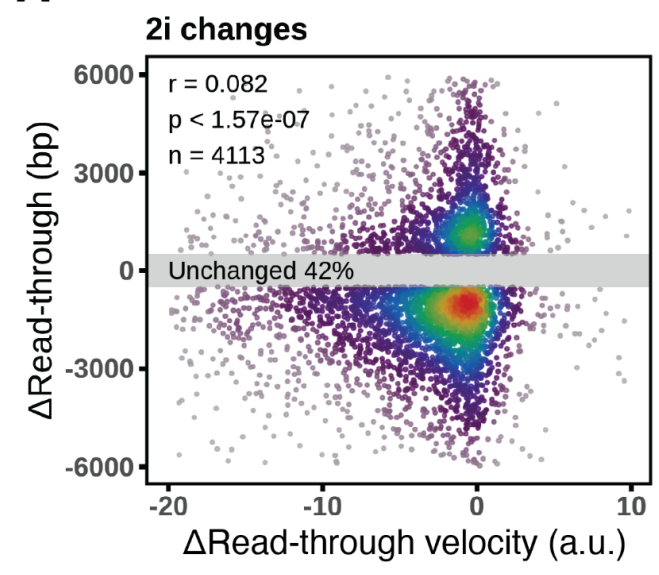

B

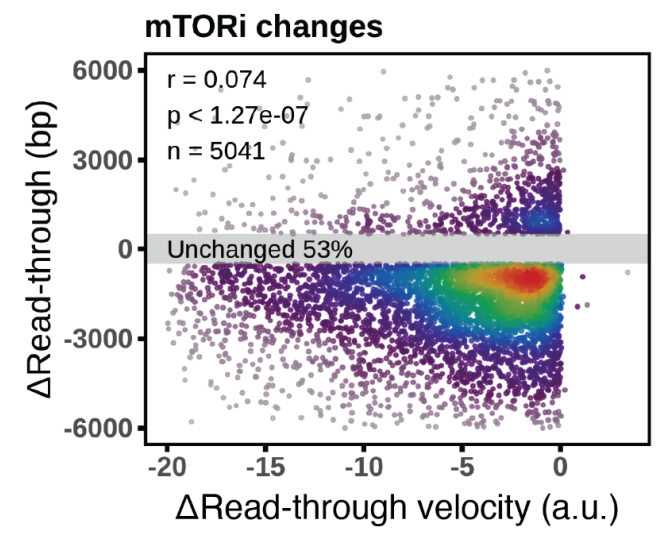

C

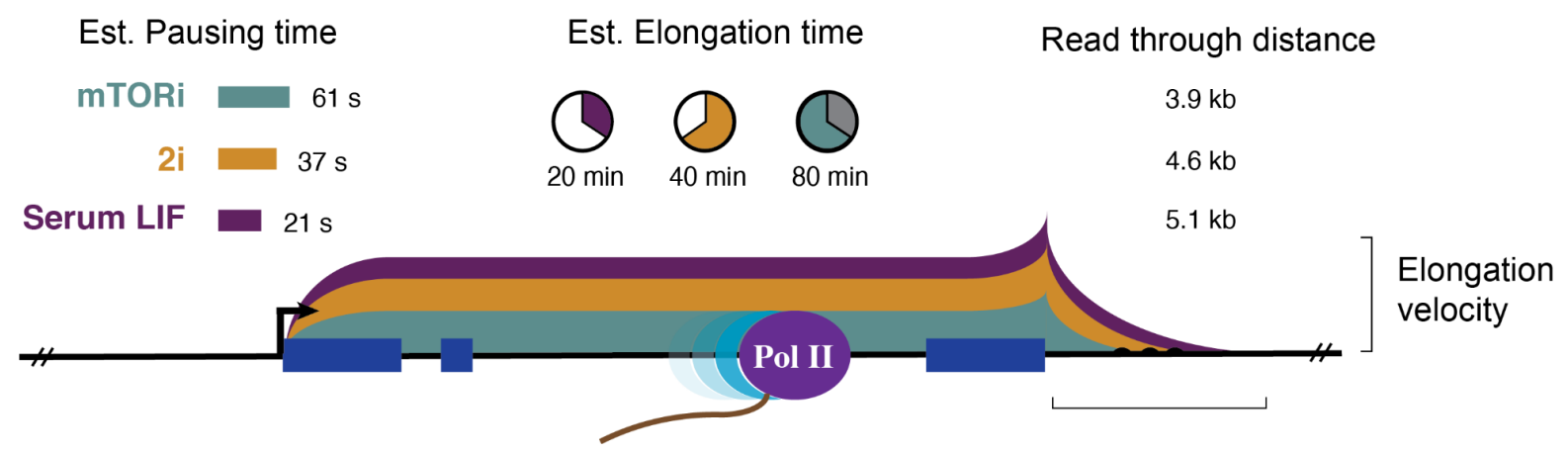

Figure EV6. Elongation velocity and read-through distance association.

A-B. Scatter plots of elongation velocity changes and read-through distance changes of $2 \mathrm{i}$ and mTORi transitions.

C. Schematic of RNA transcription dynamics in mESC pluripotent states. Elongation velocity was scaled according to GRO-seq measurements, read through distances were from TT-seq termination window coverage. 